\title{
Eradicating Terrorism in Asymmetric Conflict: The Role and Essence of Military Deterrence
}

\author{
Mustafa Cosar Unal (1) and Petra Cafnik Uludağ \\ Department of Political Science and Public Administration, Bilkent University, Ankara, Turkey
}

\begin{abstract}
This study quantitatively and qualitatively analyzes the impact and effectiveness of Turkey's deterrence-oriented incapacitation effort throughout Turkey's PKK conflict (1984-2018). By employing vector autoregressive (VAR) analysis, this study quantitatively finds that incapacitation did not reduce PKK violence over the long term and yielded a short-term counterproductive effect. Descriptive analysis asserts that while incapacitation had important mid-term deterring effects, it did not have any sustainable mitigation on the PKK insurrection. This is because, as this study argues, these deterrent impacts were not strategically converted into political gains/results. Considering the latest phase of the conflict, in which Turkey's intrastate strife has become increasingly regionalized and lately internationalized in military and political terms with the emergence of the Syrian civil war, particularly the rise of the People's Protection Units (YPG), this study claims that the sole application of an incapacitationoriented eliminationist approach has become less relevant and less effective. The study suggests that deterrence should be considered within the strategic tit-for-tat game to force/compel the non-state actor to make the conflict more manageable by transforming it in a strategic way, in which strategy of deterrence is to be attached to visionary, long-term, and viable grand strategic political end-states and to be considered within the grand bargaining game.
\end{abstract}

\section{KEYWORDS}

Deterrence; terrorism; counterterrorism (CT); incapacitation; Turkey; PKK; counterinsurgency (COIN); insurgency; military operations

\section{Introduction}

The efficacy of deterrence, as a counterterrorism (CT) strategy and in its particularity after the end of the Cold War, is a widely disputed issue. While most scholars claim that deterrence is ineffective against terrorism in a generic sense, ${ }^{1}$ some argue that it can be an effective tool under certain conditions. ${ }^{2}$ By the same token, while some argue on the efficacy of "military deterrence" in a CT campaign, ${ }^{3}$ others find it not only ineffective but also counterproductive. ${ }^{4}$ However, it should be noted that part of the reason for differing results and arguments on the efficacy of deterrence stems from the differing methods, contexts, scopes, and data used, in addition to contesting approaches and mindsets when analyzing deterrence.

This study focuses on the efficacy of Turkey's deterrence effort in its counterterrorism campaign (CT) against the Kurdistan Workers' Party (Partiya Karkerên Kurdistanê, PKK). This effort has been underway for almost four decades. This study uses a quantitative

CONTACT Petra Cafnik Uludağ $\otimes$ petra@bilkent.edu.tr $\Theta$ Department of Political Science and Public Administration, Bilkent University, 06800 Bilkent, Ankara, Turkey. 
technique and a qualitative (longitudinal) analysis. Turkey's PKK conflict serves as a rich case given Turkey's prolonged military deterrence effort in its CT campaign, the PKK's resilience by adapting to shifting contingencies in the region, and the changing security environments.

The PKK is the latest incarnation of an ongoing Kurdish struggle in Turkey existent since the Ottoman times. The multi-decade PKK insurrection is not only the bloodiest but also the longest in Turkey's modern history. Born of the new left wave of political uprisings, the PKK was officially founded in 1978. It launched its armed struggle six years later in 1984. PKK violence has been impacting the Turkish state in political, social, and economic realms, resulting in high human casualties, political instability, and economic burdens that have dramatically damaged the country's aggregate welfare. ${ }^{5}$ During the entire span of the conflict (1984-2018), nearly 6,200 civilians, and roughly 7,500 security forces members (including soldiers, law enforcement units, and armed village guards) lost their lives while many more were injured (See Appendix-A for details). ${ }^{6}$ During the same timeframe, a total of 32,562 PKK militants were neutralized, while another 1,566 were injured and 8,102 were captured (alive).

Turkey, similar to other states facing internal insurrections, has always conceptualized the PKK in a framework of terrorism. The nature and characteristics of the PKK are a contentious issue. However, through multi-dimensional analyses, Ünal argues that while the PKK's actor-oriented character reveals its insurgent nature, its action-oriented character points at terror activities - in a volatile manner-aiming at different strategies. These include-fitting the conceptualization offered by Kydd and Walter ${ }^{7}$-attrition, intimidation, spoiling, and provocation.

To counter the PKK insurrection, Turkey's measures have revolved around the notion of military deterrence with an enemy-centric approach, using the counterinsurgency (COIN) jargon. The Turkish army clearly quelled the PKK during the confrontation phase (1984-1993/94) when the PKK pursued a capacity-oriented fight and employed the Maoist strategy of a "people's war" to gain territorial control over southeastern Turkey. ${ }^{8}$ However, acknowledging its military defeat in the 1993-94 period, ${ }^{9}$ the PKK was able to shift to other strategies as an adaptive insurgent organization-as elaborated later in this paper. The PKK has maintained its threat level by leaning more on the dynamics of asymmetrical warfare (i.e., "indirect challenge” by targeting Turkey's will to fight) and escalating the violence. ${ }^{10}$

Overall, the main thrust of Turkey's effort has focused on incapacitating (killing, injuring, and capturing) PKK militants and containing the PKK ideology. Certain accommodative policies - with a population centric approach aimed at removing legitimate grievances and root causes-were adopted in the early 2000s. ${ }^{11}$ With the exception of the fractured resolution processes (known as the "Kurdish Opening" in 2009-2011 and the "Resolution/Peace Process" in 2013-2015) wherein the parties attempted to engage in a de-facto yet unofficial ceasefire, state efforts to annihilate the PKK through security operations have been ongoing in varying scales throughout the volatile conflict. $^{12}$ The common dictum in the state's narrative against the PKK has long been to continue military operations "until no terrorist remains." ${ }^{13}$ Once the latest peace/ resolution attempt was disappointedly crippled in mid-July 2015, violence re-escalated immediately. Turkey conducted air strikes on the PKK safe-haven in northern Iraq to launch preventative CT operations that incapacitated the PKK. Tensions in today's 
Turkey are at a peak due to the latest developments in the Syrian Civil War. The territorial control of northern Syria by the PKK's Syrian branch, The Democratic Union Party (PYD), and its armed apparatus the People's Protection Units (YPG) particularly, alerted Turkey to the political and military strengthening of pro-PKK entities in the region.

In light of the above, this study analyzes the impact and effectiveness of Turkey's military deterrence effort throughout the conflict: did incapacitating/neutralizing PKK members (as implied by the motto) result in the state's goal of significantly reducing levels of PKK-initiated violence? To address this question, the study employs the vector autoregression (VAR) technique to measure the summary of interrelated dynamics between Turkey's use of force, i.e., military deterrence, and PKK-induced attacks in the 34-year span. Second, to supplement the quantitative analysis, this study longitudinally analyzes different conflict processes from 1984 to 2018 to examine Turkey's military deterrence effort and its efficacy to deter PKK violence.

This study makes significant contributions to the literature with the method and data used. It provides both quantitative and qualitative analyses to complement one another for more reliable results. First, the bulk of the research on the Kurdish Question and PKK terrorism is qualitative in nature and does not detail the shifting characteristics of violence in different phases of the conflict. This study fills this gap by analyzing how the conflict unfolded through shifting security environments based on deterrence and its impacts on the varying characteristics of incurred violence. This analysis crystallizes the evolutionary phases for the entire span of the conflict. Second, a limited number of quantitative analyses exist on the case of the Turkey-PKK conflict and those analyses either focus on different issues, ${ }^{14}$ or they are descriptive in nature. ${ }^{15}$ This study uses the vector autoregressive (VAR) model, which has thus far only been used in a limited number of quantitative studies on terrorism and never on this topic. ${ }^{16}$ Studies that have used vector-autoregressive models focus on the relationship between economic issues and terrorism. ${ }^{17}$ So, this study tests a hypothesis-on the efficacy of military deterrence and the logic of "until no terrorist remains"-that has never been quantitatively tested in the Turkish case. This study does so to supplement the qualitative analysis; the VAR results provide the summary of the impact of incapacitation-through military deterrence-on the PKK-induced violence. VAR, as opposed to other time series analyses, captures and incorporates the lagged effects of incapacitation as a vector (smoothing seasonality issues) throughout the process. Third, this study utilizes two distinct datasets from the official government database and Global Terrorism Database, GTD institutional database and uses two different measurements of terrorism to cross check results.

This study first summarizes the literature on the theory of deterrence and related approaches in counterterrorism and counterinsurgency (COIN) and discusses prior research findings. Next, it introduces Turkey's counterterrorism efforts against the PKK, briefly discussing how these eliminationist strategies relate to the notion of deterrence, and reviews the findings from prior research on Turkey's counterterrorism efforts. Third, it runs VAR analyses for the 1994-2018 period. Then, it briefly assesses different periods/ cycles of the conflict and examines incapacitation trends throughout the 1984-2018 period. 


\section{Literature review on deterrence in counterterrorism}

Two competing approaches address the logic of maintaining state security against the contemporary threat of terrorism. Their perception of terrorism determines the understanding of how it should be countered. While some believe that the sole reasons behind terrorism are political, where terrorism is perceived as a deliberately selected political tool to reach a specific political end, others ${ }^{18}$ see terrorism as a consequence of social grievances related to certain legitimate deprivations and deficiencies constituting a fertile environment to foster political violence. The first approach tends to perceive terrorism as a starting point (i.e., the cause itself) isolated from its social, political and economic dynamics, while the second approach tends to understand terrorism as an eruption of perceived injustices and deprivations rooted in social, economic and political contexts (i.e., a consequence). ${ }^{19}$ Such a dichotomy in the perception of terrorism has resulted in a bipolar axis of counterterrorism policies ranging from hard-line to soft-line. Deterrence is mostly used by the hard-liners, rendering military forces primarily responsible for countering terrorism. Accommodative/anti-defiance policies, on the other hand, used by the soft-liners, relies heavily on the responsibility of the civilian law enforcement. $^{20}$

In the COIN literature, deterrence versus accommodative/anti-defiance policies relate to the enemy-centric (a.k.a. iron-fist) versus population-centric COIN (a.k.a. motivefocused) approaches. ${ }^{21}$ The fundamental difference between the enemy-centric and the population-centric COIN is not so much the use of force or the lack thereof, but rather the end toward which it is used, and the way in which it is used. Deterrence sees the use of force against the insurgent adversary as an ultimate way to win the insurgency. ${ }^{22}$ In other words, once the insurgent is fully eliminated, everything else, including the favorable political climate, will follow. Force is used as an offensive, and the role allocated to the key population is marginal at best. Almog ${ }^{23}$ for example, offers a new conceptualization of deterrence necessary for COIN campaigns, ${ }^{24}$ one he calls "cumulative deterrence." Cumulative deterrence is based on the number of victories producing increasingly moderate behavior of the adversary and shifts in the adversary's goals, eventually minimizing the conflict, making negotiations possible. ${ }^{25}$

The population-centric COIN, however, is different. Its primary focus falls on the protection and winning the hearts and minds of the key population. ${ }^{26}$ Thus, force is used for protection of this population in a more defensive manner. That is not to say that this approach uses less force. Rather, the underlying idea is to successfully separate the insurgents from the key population by offering protection. This, in turn, helps the counterinsurgent to restore credibility in the government. ${ }^{27}$ At the same time, this approach envisions the use of necessary political measures designed to address popular grievances that gave rise to the insurgency in the first place. Such a two-tier method aspires to restore legitimacy of the government, while using the minimum force necessary. ${ }^{28}$

Deterrence, in the field of CT and COIN is mostly used in the enemy-centric and deterrence-oriented policies often incorporating punitive approaches. Hence, deterrence in general and military deterrence in particular implies that terrorists' behavior can be affected if that behavior's costs and benefits change. Appropriate policies can exert a deterrent effect on terrorist activities by imposing constraints on the expected utility 
of terrorist activities. ${ }^{29}$ Raising the costs of terrorist activity has many different aspects: raising the certainty and severity of the punishment and apprehension by imposing heavier sanctions, increasing logistical complexity and decreasing the probability of success for terrorist attacks by tightening security measures of the potential targets, increasing the threat of death and injury by conducting military operations, and so forth. ${ }^{30}$

While deterrence implies either raising the costs or reducing the benefits of terrorist activity, ${ }^{31}$ most governments have exclusively relied on raising costs. ${ }^{32}$ The reason for this exclusive reliance is due to the uncertainty and unpredictability of terrorism's benefits as well as the complexity of reducing the terrorists' perceived benefit. ${ }^{33}$ Reducing the benefits, on the other hand, refers to measures that increase the reward for withdrawing from terrorist activity, such as social reforms and civil rights developments. ${ }^{34}$ The reward giving is related to defiance (or legitimacy) theory, which focuses on how the audiences of terrorism perceive and respond to actions in a CT campaign, and recommends accommodative strategies. Defiance theory suggests that CT policies are more effective if and when they are perceived as legitimate and procedurally fair by the society. ${ }^{35}$ Many studies argue that perceived justice is a great determinant of people's feelings and actions in social interactions. ${ }^{36}$ Applications of legitimacy/defiance theory in the field of terrorism have revealed that the intended cost of impositions of deterrence-based repressive policies might not be perceived by the target population the same way they are perceived by their implementers. ${ }^{37}$ Policies such as excessive military strikes and unjustifiably heavy criminal sanctions decrease the government's perceived legitimacy. ${ }^{38}$ Raising the severity and intensity of sanctions and increasing the threat of death or injury might create mythologies of martyrdom, strengthen group solidarity and resilience, and incite revenge, rage, and retaliatory sentiments, ${ }^{39}$ as opposed to creating a sustainable deterrent effect on the perpetrators of violence. ${ }^{40}$ Strengthened group dynamics are particularly common in ethnicity-based terrorist settings with strong bonds between specific social segments and the terrorist group. ${ }^{41}$

Many studies have examined the effectiveness of deterrence in countering terrorism; however, the results have been inconsistent. While some studies have found a sound basis for deterrence strategies, ${ }^{42}$ most of them have not, ${ }^{43}$ and some have even argued that deterrence might be counterproductive. ${ }^{44}$ Trager and Zagorcheva, ${ }^{45}$ emphasizing political solutions, claim that deterrence can work against terrorism for two reasons: the terrorism-state relationship is not zero-sum; and, powerful states have an ability to influence their political aims. Trager and Zagorcheva further note that deterring a terrorist group is significantly easier if the group's motivation is relatively low and/or if the government the terrorist group opposes is able to accommodate at least some of the terrorists' goals. Betts ${ }^{46}$ disagrees with Trager and Zagorcheva asserting that terrorists are irrational, very highly motivated and ready to lose their life. Besides that, their values and their way of life do not provide much of value against which states can retaliate. Miller ${ }^{47}$ agrees with Betts and adds that "deterrence is least effective when terrorist movements are fragmented, when terrorist groups are decentralized, and when individual terrorists are willing to engage in self-sacrifice." Nonetheless, deterrence is not impossible. It is more likely to be effective "against relatively unified movements and groups, and against individuals that act egoistically." ${ }^{\prime 8}$ In situations less suitable for deterrence Miller suggests proactive policies: "preventing new members from joining terrorist groups and preventing sympathizers from supporting terrorist groups. Although these are both 
forms of deterrence, they are directed against those who are not yet in a terrorist group." 49 Some studies have also found that deterrence-oriented repressive measures do not affect terrorist activity, but do produce increased violence after a lag period. ${ }^{50}$ Thus, Almog has asked a question of whether it is possible at all to deter suicide bombers. His study shows that it is possible by threatening those close to the bomber. Nonetheless this tactic may backfire if it fails. ${ }^{51}$ But it has to be noted that not all terrorists are as willing to die as a suicide bomber, ${ }^{52}$ especially leaders, thus they may be more easily deterred. $^{53}$

When considered in an intrastate conflict, deterrence very often has a substituting/ transferring effect in insurgents' violent actions. This is because violent groups adapt and innovate, continuing their campaigns through different modes and tactics to attack new, less-guarded targets. Diversification takes place when "organizational viability is threatened, overshadowing the costs of expansion" ${ }^{54}$; diversification's aim is to challenge counterterrorism and to increase the prospects for a successful attack. ${ }^{55}$ Horowitz and others show a clear correlation between diversification and favorable political outcomes: diversification increases the number of possible targets that might be attacked; defending multiple targets introduces new vulnerabilities; finally, these vulnerabilities enable the militants to circumvent the defense, which in response pushes the state toward a political solution. ${ }^{56}$ Militant organizations are expected to diversify when their survival is at risk. ${ }^{57}$ Thus, repression of militant groups may result in less favorable outcomes for the state. ${ }^{58}$ In this respect, deterrence is considered a zero-sum game ${ }^{59}$ and counterproductive in many cases. ${ }^{60}$ Deterrence, as a sole CT policy, has also been found to be totalistic and extreme, as the use of excessive force outside the civilian rule of law inevitably results in collateral damage. ${ }^{61}$

One of the more extreme strategies of deterrence is decapitation, a tactic seeking to kill or capture insurgency leaders. Decapitation's effect depends on "the size and degree of compartmentalization of the group." ${ }^{\prime 2}$ Smaller, structured groups based on close relationships will suffer more, ${ }^{63}$ while larger, more anonymous and decentralized groups, will remain only modestly affected. ${ }^{64}$ The killing or capturing of a charismatic leader, especially of a small group, has rarely caused the demise of a terrorist group. In a few cases, decapitation even turned the leader into an inspirational martyr. ${ }^{65}$ More resilient groups have retaliated with terrorist attacks. ${ }^{66}$ Jordan's study ${ }^{67}$ shows decapitation to be ineffective and counterproductive, strengthening organizational resilience and popular support. ${ }^{68}$ Manne $^{69}$ also claimed that decapitation might work only in limited circumstances. Johnston, ${ }^{70}$ on the other hand, found decapitation effective in either reducing or ending conflicts even in decentralized organizations. Price ${ }^{71}$ applied a long-term effectiveness measurement and argued that decapitated terrorist groups have a significantly higher mortality rate; early decapitation has greater effect; religious groups, are less resilient than nationalist groups after experiencing decapitation probably because of the important role of the leader. ${ }^{72}$

In sum, several empirical studies have found deterrence as CT ineffective in the long run and counterproductive in the short run, indicating that deterrence policies create a substitution effect. ${ }^{73}$ Thus, as Wenger and Wilner argue, deterrence should be used as a supplementary/complementary tool in states' CT strategies rather than a focal point of their efforts. ${ }^{74}$ By leaning on a Clausewitzian notion of instrumentality of war, this is best underlined by Schelling's ${ }^{75}$ argument. He claims that deterrence, as part of the art of war, 
is to be utilized in the context of the diplomacy of violence for coercing the opponent in an acquisitive way rather than punitive-toward the feasible outcome.

Accommodative policies aiming at diminishing defiance within society are found to be much more effective in curbing terrorism because they increase the level of government legitimacy in the eyes of the population by upholding procedural justice and fairness. ${ }^{76}$ Many ${ }^{77}$ have argued that terrorists do not act rationally. Therefore, increasing the material costs of carrying out terrorist attacks would not sustainably eradicate terrorism. Engaging in terrorism is not a simple rational decision; rather it is a reaction to the grievances buried in social, economic and political contexts. Alleviating grievances in the political context and fixing social and/or economic deficiencies is considered to be a more just and legitimate approach, achieving both the removal of fertile ground for terrorism and the reduction or elimination of violence. ${ }^{78}$ Nonetheless, accommodative strategies are criticized as well. Wenger and Wilner, ${ }^{79}$ among others, describe terrorists as "rational fanatics" and claim that there is rationality at the organizational level of terrorist groups. Wenger and Wilner argue that although individual members may embrace extremist and irrational views, organizations have practical and rational priorities and, thus, use violence to achieve a variety of political goals. Moreover, accommodative strategies are criticized for rewarding the use of terrorism as an effective tool for political ends as well as legitimizing terrorists by officially recognizing their efforts. ${ }^{80}$

\section{Turkey's deterrence campaign and prior research on campaign effectiveness}

In its prolonged endeavor to address the PKK problem, Turkey has implemented various CT policies that fall under two camps: deterrence vs. defiance or enemy-centric vs. population centric approaches. In the initial years of the conflict, Turkey responded with an iron-fist approach entailing harsh security measures. Along with intense military action on the ground, the Turkish military conducted large-scale military operations including cross-border field operations in Northern Iraq (the PKK's long-time sanctuary) until the 2000s. In addition, the Provisional Village Guard System (GKK), in which 40,000 to 95,000 villager volunteers were trained and armed to guard villages against PKK militants, was adopted in April 1985. ${ }^{81}$ A State of Emergency Rule (Olağanüstü Hâl, OHAL) was proclaimed in July 1987 in eleven provinces in the Southeast that faced substantial PKK activities and violence. Most importantly, from the early 1990s until 2000s, state authorities adopted a policy to forcibly evacuate the inhabitants of remote villages and resettle them into larger villages for better control of the region. ${ }^{82}$ This evacuation policy affected a population of six million across 2,000 villages. ${ }^{83}$ Moreover, as a result of Turkey's coercive diplomacy in 1998, PKK camps were removed from Syria which lead to the expulsion and capture of PKK founding leader, Abdullah Öcalan (February 1999).

From the deterrence approach, these policies were designed to impose costs on PKK activities, including increasing the certainty of apprehension and imposing heavier sanctions through OHAL, proactively decreasing the probability of success of PKK attacks through large-scale (including cross-border) military operations and increasing the logistical complexity and reducing the mobility of PKK members through GKK. The goal was to annihilate the enemy, as would be the case in conventional (attrition) warfare. ${ }^{84}$ Thus, 
the underlying assumption of Turkey's enemy-centric approach was that conflict would end once all insurgents/terrorists had been incapacitated (killed, injured, and/or captured).

It should also be noted that Turkey also implemented certain accommodative policies in the early years of the conflict (e.g., lifting the ban on the private use of the Kurdish language in 1991, the then President Özal's resolution attempt in 1993, the Southeastern Anatolian Project, recognition of Nevruz ${ }^{85}$ as a national public holiday in Turkey in 1995). However, despite these, nevertheless weak and narrow, accommodative policies, the general framework of the Turkish CT campaign mostly reflected an enemy-centric approach between 1984 and 2000. The majority of Turkey's accommodative policies and reforms which aimed at diminishing defiance in the Kurdish region occurred after the early 2000s with Turkey's democratization efforts and full European Union (EU) membership trajectory. ${ }^{86}$ Turkey responded to certain root causes and legitimate parts of the Kurdish grievances: certain restrictions on the Kurdish language were lifted after the 2000s; broadcasting and publishing in Kurdish in public and private media were allowed as of September $2003^{87}$; the state of emergency rule (OHAL) was removed from the region by 2002; the State Security Courts (SSCs) with special antiterrorism features, that reviewed PKK-related cases to easily incarcerate PKK members, were abolished in 2004-though the core characteristics of the Turkish Anti-terrorism Law remained unchanged; forced evacuations ended and the "return-to-village" project was adopted in the early 2000s. Moreover, Turkey granted two broader amnesties (i.e., the Return Home Bill of 2003 and the Effective Repentance Law of 2005). ${ }^{88}$ So, after the early 2000s Turkey shifted to a mix of both enemy-centric deterrence and population-centric accommodative policies. ${ }^{89}$

Turkey's changing approach implied that physical obliteration was not necessarily the only way to achieve the government's desired end state. Turkey incorporated more policies in the social, economic, diplomatic, and political realms during the Justice and Development Party's (AKP) initial years. ${ }^{90}$ However, this varied approach did not then entirely eliminate the use of military deterrence. Rather, military force was used more selectively and discriminately than in the earlier years of the conflict. Along with the scale of military operations, the role of the Turkish army has changed from leading in the early years to supplementary in the recent CT campaigna change which has also paralleled the change in the civil-military relations. Regardless of the variations in the nature of Turkey's CT campaign, military operations have been continuous throughout the conflictwith the exception of the two consecutive resolution processes (2009-2011 and 2013-mid 2015). The sole purpose of military operations was to have a deterrent impact on the PKK through incapacitation. The quantitative focus of this study, then, is to determine whether incapacitation helped mitigate the PKK's insurrection. ${ }^{91}$

Many studies have analyzed Turkey's responses, and most of them have found Turkey's deterrence policies ineffective in producing a sustainable deterrent on the PKK. ${ }^{92}$ Today's escalated levels of violence serve to show that PKK activities have not been deterred. The bulk of the literature on this topic has been qualitative, and there has been little research based on quantitative data.

Prior research on Turkey's CT measures also indicates the failure of harsh, deterrencebased responses in reducing the PKK insurgency. Tezcür ${ }^{93}$ empirically proves why incapacitation did not lead to the PKK's demise by explaining individuals' participation in the PKK insurgency. Ünal, ${ }^{94}$ on many accounts, finds Turkey's deterrence policies ineffective in the long run despite certain mid-term deterrent impacts on PKK violence. Kim and 
Yum, ${ }^{95}$ on the other hand, find mixed results for Turkey's deterrence effort in their descriptive study, concluding that deterrence policies may work for particular cases under certain conditions but do not cure the problem of terrorism. Kocher ${ }^{96}$ argues that the decrease in PKK-initiated violence was based on strategic factors rather than popular support, claiming that the radicalization of Turkey's Kurds by the state policies in the 1990s was overstated. Ünal, ${ }^{97}$ Aydinli, ${ }^{98}$ and Kayhan-Pusane ${ }^{99}$ conclude that CT operations conducted by the Turkish army had a deterrent effect on the PKK's territorial combat but did not marginalize the PKK insurrection. Ünal ${ }^{100}$ explains this lack of marginalization: once the PKK had been defeated militarily in the fight over territory, the PKK directed its terrorist attacks toward big cities using different tactics, indicating a substitution effect rather than a deterrent one.

\section{Research design and data}

This section discusses the conceptual model, data, variables used in the quantitative analysis with operational definitions, method of analyses, the empirical model (constructed VAR models), and the procedures of VAR analyses.

\section{Conceptual model}

\section{Quantitative analysis}

The focus of the quantitative analysis is to address Turkey's military deterrence effort aimed at incapacitating (killing, injuring, and capturing) the PKK's armed militants and whether that effort reduced the PKK-induced violence within the thirty-four-year period (1984-2018).

In addressing the research question (RQ), this study analyzes the entire period of the conflict except the decisive/confrontation phase in which parties engaged in a more direct territorial and capacity-oriented fight in the physical realm. Therefore, it focuses on the eliminationist approach to assess the value of Turkey's neutralizing/incapacitation effort through military deterrence in an intrastate conflict reflecting low intensity and asymmetry.

The study runs a VAR analysis to examine the impact and effectiveness of Turkey's overall deterrence effort between May 1994 and December 2018 and to identify whether the incapacitation of PKK militants helped mitigate the PKK-initiated violent attacks and contributed to the PKK's destruction through attrition, as implied by the motto "until no terrorist remains."

\section{Qualitative analysis}

The model used in the quantitative analysis is limited and can only be used to analyze Turkey's military deterrence effort in an aggregate manner (the summary of overall impact of incapacitation in thirty-four years of military action). Due to the limitations of only capturing the endogenous dynamics between the use of force (military deterrence) and PKK-induced attacks, this study also engages in a longitudinal (process) analysis. Strategic aims of conflict parties are briefly discussed to explain periodical (short- and meso-term) deterrence impact resulting from those other than military deterrence. The aim of the longitudinal analysis is to portray other determinant factors as independent variables that affect the violence level (e.g., intentional decrease in violent attacks as a result of certain strategic choices). 


\section{Data and variables}

\section{Quantitative analysis}

This study uses a dataset that was extracted from the Global Terrorism Database (GTD) and the official government database. The dataset includes violent incidents made available to the press, by collecting data from open sources. Since the GTD data for 2018 has not yet been released, the dataset is completed with official figures from the government's weekly press release for 2018. The datasets used in the VAR analyses include monthly intervals of violent incidents covering the period between May 1994 and December 2018. ${ }^{101}$ Coded variables include two different measurement of terrorism: (i) the number of casualties as a result of PKK attacks and (ii) the number of violent attacks carried out by the PKK that resulted in casualties and property damage (VIOLENCE) and (iii) the measurement of use of force (Turkey's military deterrence effort), that is the number of incapacitated (killed, injured, and captured) PKK militants (INCAPTER). ${ }^{102}$ All of these time series trends have been analyzed through the VAR technique to identify the association, if any, between these variables as well as their magnitude and direction for the span of nearly thirty-four years. In so doing, the study seeks to identify whether or not the impact of incapacitating (killing, injuring, and capturing) armed militants has been decreasing insurgent violence, thus achieving the goal of military deterrence. The variables used in the analyses are listed in Table 1, followed by their operational definitions.

It should also be noted that cross-national datasets like GTD are known to have certain limitations in terms of reporting and coder issues. However, the data used, particularly for earlier periods (pre-2000) were extracted from a relational dataset supplemented or crosschecked with the Study of Violent Groups (ISVG). There are considerably less reporting problems for the GTD data after the 2000s. ${ }^{103}$

Moreover, to make the quantitative analysis stronger and to cross-check the results, the authors also ran the same analysis using a different incident-level dataset from the government. This is a secondary dataset drawn from the study of Ciftci and Kula ${ }^{104}$ covering the period of 1995-2010, including the same three variables used in the main VAR analyses. The results of the secondary analysis are presented in Appendix-C. To make the results comparable, the authors presented the results along with the results from the GTD dataset. The results are very similar to those of the main VAR analyses.

\section{Qualitative analysis}

An additional dataset giving aggregate level annual data points from 1984 to 2018 has been used primarily for supplementary descriptive analyses (i.e., annual aggregate level of violence and casualties, number of killed, injured, captured, and surrendered PKK militants, and so forth).

Table 1. List of variables from both datasets (used for the VAR analyses).

\begin{tabular}{ll}
\hline Variables & \multicolumn{1}{c}{ Explanation } \\
\hline VIOLENCE & Number of casualties (killed, injured civilians and security force members, government staff). \\
NVIOLENT & Number of violent attacks that resulted in casualties and property damages. \\
DATE/MONTH & Monthly observation points. \\
INCAPTER & Number of incapacitated (killed, injured, and captured) PKK militants. \\
\hline
\end{tabular}


Violent incidents in all datasets refers to the acts of extreme aggression and physical force that mostly resulted in human casualties as well as damage to property. Thus, violence measures casualties (killed and injured) as well as damaged public or private facilities due to PKK attacks. Use of force by deterrence denotes the incapacitated PKK militants by the total number of killed, injured, and captured PKK militants as well as PKK attacks damaging property.

\section{Empirical (VAR) model for quantitative analyses}

To address the RQ, the authors used the VAR technique, which particularly analyzes the underlying correlation among multiple time series variables to identify the dynamic structure among those variables. ${ }^{105}$ This study, as explained earlier, is intended to analyze the relationship between the incapacitated PKK militants as a result of military deterrence and the level of PKK-induced violence to determine if incapacitating PKK militants has had a decreasing impact on PKK violence in the thirty-four-year span. To verify the results, it does so separately by using different measurements of terrorism: the number of casualties (VIOLENCE) and the number of attacks (NVIOLENT).

$\mathrm{VAR}$, as a technique in general, is a multivariate autoregressive (n-equation, $\mathrm{n}$-variable) model in which each (endogenous) variable is regressed on its past (lagged) values and past (lagged) values of the other (n-1) endogenous variables (and current values of the exogenous variables, if any) in the system to capture and characterize the structural dynamics among time series variables-in this case, the use of force (INCAPTER) and PKK-induced violence (VIOLENCE and NVIOLENT) are incorporated in a bivariate analysis. ${ }^{106}$

This model used an aggregate approach, in which PKK-induced violence and the result of the state's use of deterrence-oriented military operations (incapacitation) are analyzed in an overall sense rather than incorporating a geo-spatial perspective. This is because the PKK has been a very centralized organization characterized by a top-down hierarchical mechanism and a tough Weberian structure. That is, the PKK's decisions for violent attacks come from a central mechanism at the macro level. The decision mechanism is highly influenced by the overall political context in their strategic interaction with the ruling authority rather than regional dynamics.

When constructing a VAR model, selecting the appropriate variables and incorporating them as endogenous or exogenous is highly dependent on the relevant theory. In low intensity conflicts, a portion of the mutually employed violence from opposing groups is determined and attributed to retaliatory sentiments as reflected in the Gandhian perspective that "violence causes violence"-the counterproductive dimension of the use of force. ${ }^{107}$ Hence, this study ran the Granger Causality (pair wise) and results supported the existence of endogeneity between the INCAPTER and VIOLENCE or NVIOLENT. These variables are incorporated into the system as endogenous variables.

To examine the effects of incapacitated (INCAPTER) PKK militants on the structural interaction with PKK-induced violence (VIOLENCE), the following form of reduced ${ }^{108}$ VAR model was constructed. The mathematical representation of the constructed VAR model at lag length " $\mathrm{p}$ "109 is as follows: 
$\begin{aligned} \text { Violence }_{t} & =\beta_{11} \text { Violence }_{t-1}+\beta_{1 P} \text { Violence }_{t-P}+\ldots+\beta_{12} \text { Incapter }_{t-1}+\beta_{1 P} \text { Incapter }_{t-P}+\varepsilon_{T t} \\ \text { Incapter }_{t} & =\beta_{21} \text { Incapter }_{t-1}+\beta_{2 P} \text { Incapter }_{t-P}+\ldots+\beta_{21} \text { Violence }_{t-1}+\beta_{1 P} \text { Violence }_{t-p}+\varepsilon_{T t}\end{aligned}$

Where:

Violence $_{t}$ is the level of violence (i.e., number of violent incidents or number of casualties) during the time period $t$ (period $t$-P),

Incapter $_{t}$ is the number of incapacitated (killed/injured) terrorists as a result of counterterrorism operations during the time period $t(t-\mathrm{P}), a_{1}$ is the constant, $\beta_{11}$ Violence $_{t-1}$ is the term representing the effect of violence variable's own past lag, $\beta_{12}$ Incapter $_{t-1}$ is the term for the other endogenous variable's past values, and $\varepsilon_{T t}$ is the white noise/disturbance (error term). More specifically, $\beta_{12}$ represents the contemporaneous effect from one-unit change of Incapter $_{t-P}$ (incapacitation) at the P lag on Violence $_{t}$ (PKK violence). ${ }^{110}$

Sandler and Enders used a similar model for analyzing the substitution effect among different modes of attacks in transnational terrorism. ${ }^{111}$ By using this model, the authors plot the impulse response function ${ }^{112}$ to identify the dynamic interrelation between the use of force (INCAPTER) and terrorist violence (VIOLENCE or NVIOLENT) to identify the effect of one on another or the structural relationship between the two.

It should be noted that the VAR models here analyze the interaction between the use of force (military deterrence) and PKK-induced violence. As briefly touched upon in the qualitative part there exist multiple factors impacting the level of PKK violence that can be considered as omitted variables in the analyses. However, the VAR analysis here aims to make aggregate look and provide the summary of the efficacy of the military deterrence as a CT policy in entire span of the conflict rather than in a single period to incur a causeeffect relationship. In that, the focus of the VAR analysis is whether or not the aggregate impact of killing, injuring and capturing PKK militants in the thirty-four-year span had a decreasing impact on the overall PKK violence as aimed by state officials with their motto of "until no terrorist remains."

Moreover, VAR is a more appropriate technique in time series analyses of endogenous variables. ${ }^{113}$ The VAR models constructed in this study incorporate the lagged effect of each time series variable to capture the interrelated dynamics of military deterrence (use of force) and incurred terrorist violence as vector in time (smoothing the seasonality) rather than a single point in time, which reflects a wider scope of interaction between variables and more precise results when compared to other time series models (e.g., SEQ, ARIMA, $\mathrm{ECM})^{114}$ and a simple bivariate analysis techniques (e.g., Correlation).

As with many other statistical analysis techniques, VAR analysis also needs to meet certain criteria for reliable results and inferences; i.e., nonexistence of unit root/stationarity, determining appropriate lag length based on fit statistics; uncorrelated residuals, etc. All necessary preliminary tests were conducted and the results met the assumptions-i.e., none of the variables has a unit root, there is no serial correlation problem (Autocorrelation LM test) among the residuals and no white noise disturbances. The appropriate lag lengths are specified based on fit statistics (e.g., Schwarz Information Criterion). The constructed VAR model meets the stability tests (e.g., CUSUM test). All detailed discussions on the preliminary steps/procedures of VAR estimates with specific preliminary test results are provided in Appendix-B. ${ }^{115}$ 


\section{Results of the quantitative analysis}

Overall, VAR estimates revealed that incapacitating PKK militants did not have a significant impact decreasing PKK violence, and thus, the sum of deterrence policies designed to incapacitate PKK militants did not bring the desired end-result: significantly reducing the PKK attacks. In fact, eliminationist deterrence efforts were found to be counterproductive in the short term. Therefore, the results strongly contradict the logic of the motto "until no terrorist remains."

More specifically, VAR estimates include two separate analyses by identifying the interrelation between incapacitation (INCAPTER) and the results of the PKK attacks (VIOLENCE and NVIOLENT) for the given period (May 1994 - December 2018).

In the first one, the response of VIOLENCE as a result of INCAPTER is analyzed. In that, it examined the impact of overall incapacitation effort on the PKK-induced violence with two separate measurements of terrorism. First, the number of casualties covering the killed and injured civilians, security force members (police, soldier and village guards), and government staff.

(Second, the relationship between INCAPTER and NVIOLENT in which the response of the number of PKK attacks is analyzed as a different measurement of PKK violence (rather than the number of casualties).

Additionally, a VAR analysis is run to analyze how state security forces (mostly military units) responded to PKK-induced violence by examining the response of INCAPTER to the PKK-initiated VIOLENCE or NVIOLENT - as analyzed through the VAR estimates.

The effect of incapacitation on the PKK-induced violence (by casualties) in the given period is plotted in Figure 1. The horizontal solid line denotes the change (response) in the level of violence (VIOLENCE) after one-unit (standard deviation) shock/impulse was given to incapacitation (INCAPTER). The line shows how the PKK-induced violence level was impacted over a ten-month period by the state's incapacitation effort. The horizontal dashed lines refer to the error band around the impulse function result. The results indicate that the response of VIOLENCE to one-unit shock/innovation given to the INCAPTER results in about seven more casualties. ${ }^{116}$ The INCAPTER's effect starts with a steady increase and reaching its peak in the fourth month and then it gradually decays and fades away by the tenth month.

As plotted in Figure 2, the number of PKK-initiated violent attacks (NVIOLENT) also shows an increase when one-unit (standard deviation) shock/impulse was given to incapacitation (INCAPTER), albeit the effect is not statistically significant since the error band never goes above the zero line.

Overall, the results indicate that incapacitating PKK militants did not impact the decrease in PKK-initiated violence. Rather, incapacitation yielded a counterproductive impact, implying that the incapacitated PKK militants did not deter PKK's ability to continue employing retaliatory violent attacks despite such intense incapacitation efforts. ${ }^{117}$ In other words, Turkey's deterrence-oriented eliminationist approach seeking PKK's demise did not have a mitigating impact on the PKK-induced violence. On the contrary, in the twenty-four-year span (May 1994 - December 2018), deterrence yielded counterproductive results in the overall sense.

To see how the security forces' incapacitation (INCAPTER) effort is affected or how the state reacted to the PKK violence, an impulse shock is given to PKK violence 


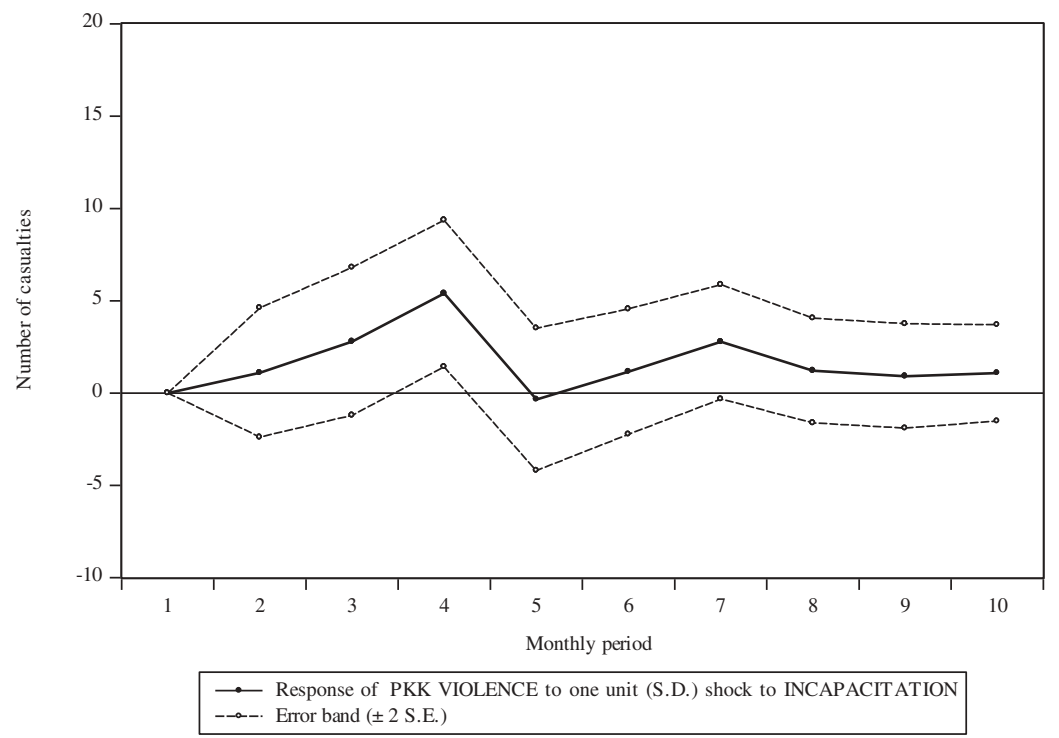

Figure 1. The response of VIOLENCE to one S.D. impulse in INCAPTER.

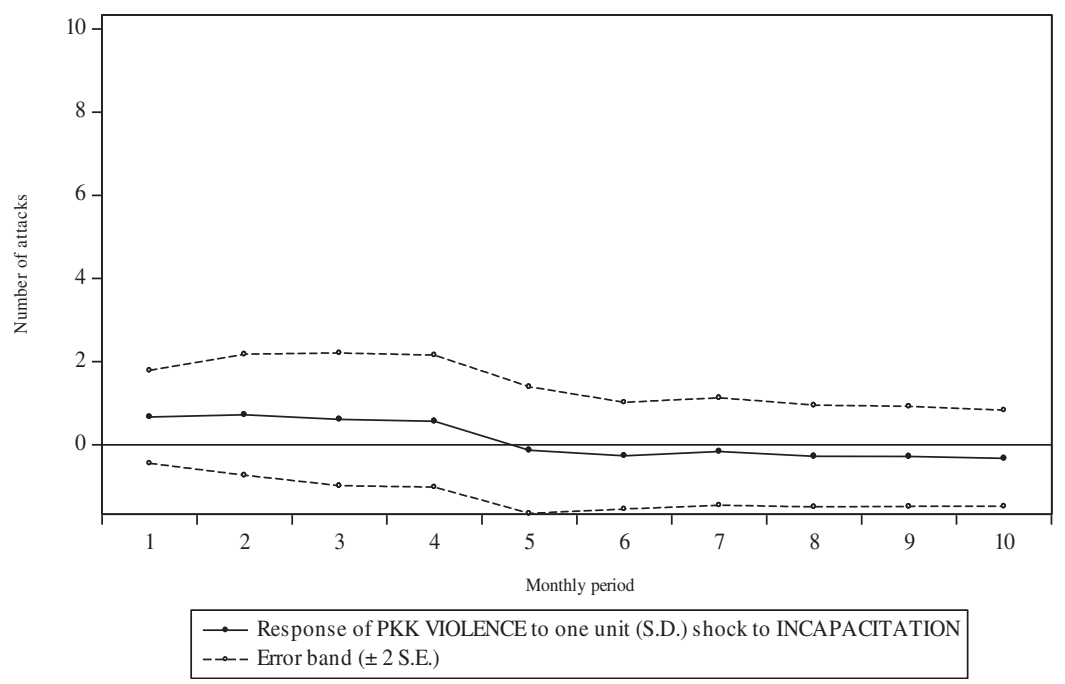

Figure 2. The response of NVIOLENT to one S.D. impulse in INCAPTER.

(VIOLENCE). The results, as plotted in Figure 3 clearly indicate that security forces conducted military operations subsequent to PKK attacks. In other words, Turkey immediately responded to PKK violence. As shown in Figure 3, results indicate an immediate and statistically significant spike in the incapacitation efforts starting from the second period. However, these incapacitation efforts gradually fall during the second month. Results for the number of PKK attacks (as a different measurement of terrorist attacks) are similar. As shown in Figure 4, results indicate a rapid military response to PKK attacks. 


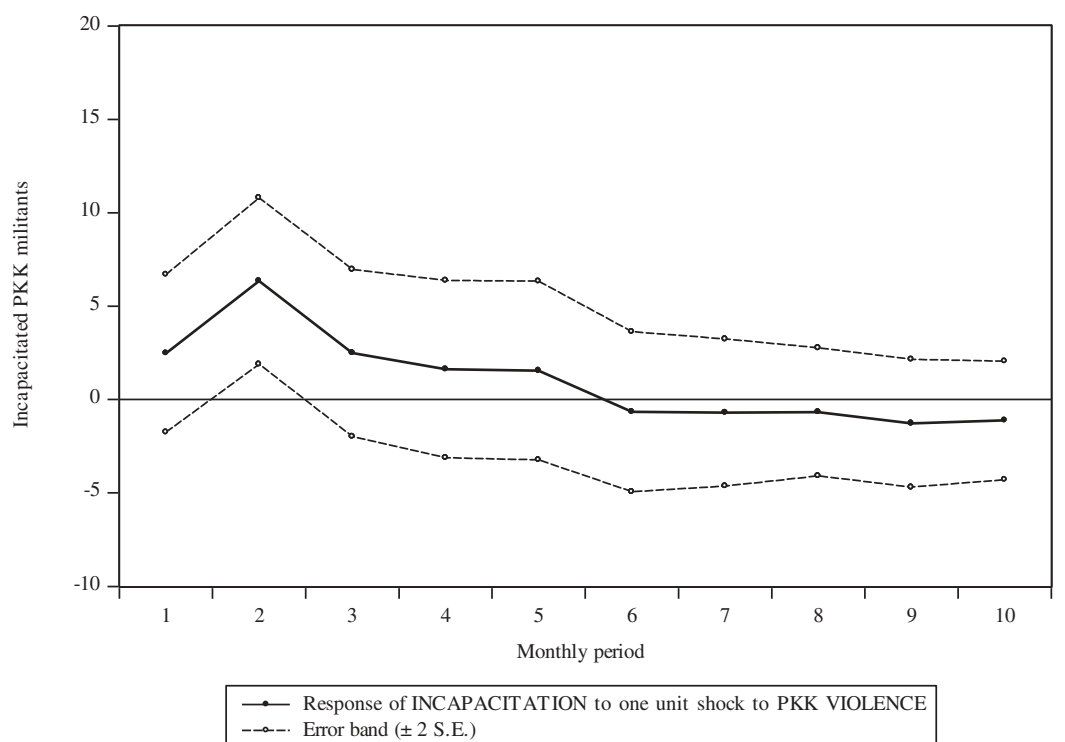

Figure 3. The response of INCAPTER to a one S.D. impulse in VIOLENCE.

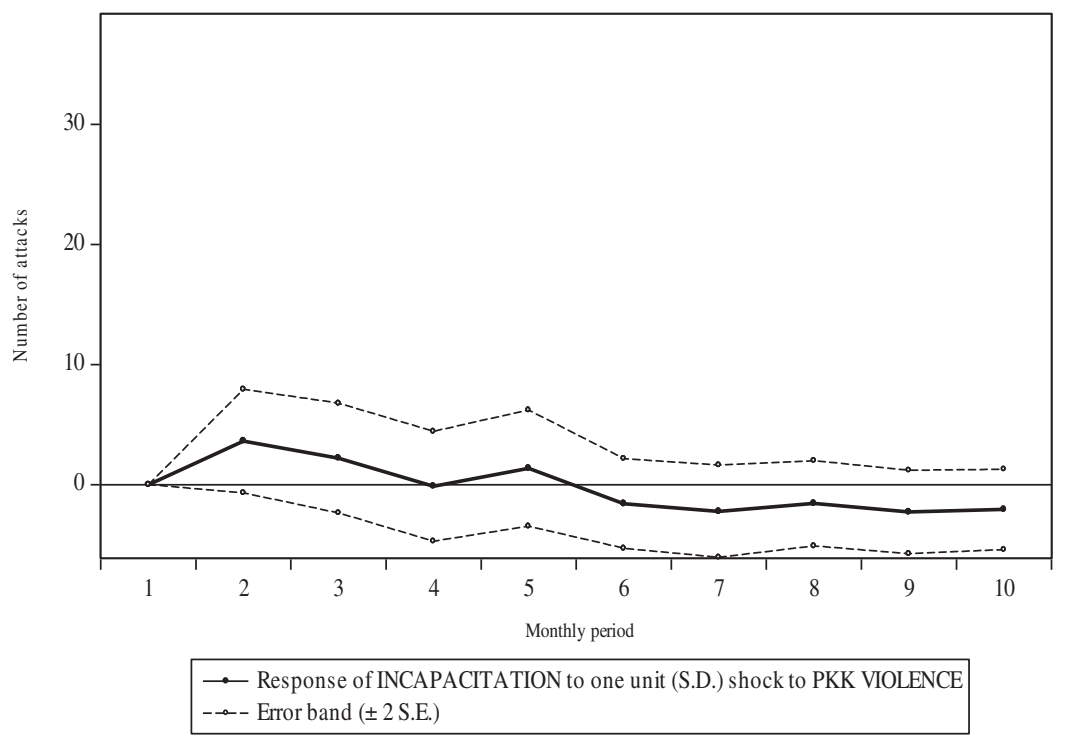

Figure 4. The response of INCAPTER to one S.D. impulse in NVIOLENT.

In the end, the results from the VAR analyses indicate that the paradigm of incapacitation-oriented deterrence, aiming to incur a significant deterrent impact on the PKK by annihilating - "until no terrorist remains"-did not help mitigate the PKK violence. As elaborated in the following section, the results shed light on Turkey's recognition of the military stalemate (in total elimination of PKK terrorists) and its negative impact on both human loss and economic cost. The military stalemate and the failure in reducing PKK 
violence down to a marginalized level constituted an important part of the reason-among others-why Turkey switched to a more conciliatory approach in the second half of the 2000s.

\section{Qualitative (longitudinal) analysis}

The PKK conflict evolved through different phases based on tit-for-tat approach in both the political and military spheres. It was influenced by changing national and international contexts that provided insight into Turkey's military deterrence effort and its impact on the PKK violence. In this regard, to evaluate the findings from the quantitative analyses, this section longitudinally reviews the conflict and its evolutionary phases, a result of conflicting parties' (Turkey and the PKK) strategic interaction from 1984-2018. The aim is to provide a longitudinal analysis to identify temporal deterrence impacts on the PKK violence and different dynamics and factors—other than "military deterrence"behind them.

\section{Deterrent impact: Military defeat}

The PKK's initial political end-state was to establish an “Independent 'United' Kurdish State" comprised of certain territories of Turkey, Iraq, Iran, and Syria. Inspired by the Cuban Revolution, the PKK resorted to the Maoist Strategy (MS), embracing a typical three-echelon structure (i.e., strategic defensive, strategic equilibrium, and strategic offensive) from Mao's “Theory of People's War."118 As specified in the PKK's founding manifesto (aka The Path for Revolution in Kurdistan) ${ }^{119}$ the PKK has imagined a revolution emanating from agrarian Kurdish peasantry living in rural areas of southeastern Turkey toward metropolitan areas. ${ }^{120}$ The war officially commenced on August 15, 1984 with two attacks in Şemdinli and Eruh Districts.

In initial terms, the PKK directly challenged and confronted the security forces and in alignment with its MS, the PKK strived to attrite the government's authority in Turkey's south and southeastern region ${ }^{121}$ by conducting attacks in places where the governmental control was weak (e.g., remote hamlets and villages, military outposts). The PKK struggled for territorial separation through a direct military victory with a grand strategy of outfighting the Turkish forces.

In the initial years of PKK insurrection, Turkey framed the PKK issue as a "bunch of bandits" and took no specific military action until 1987. The PKK's initial surge was handled by the gendarmerie, serving as a law enforcement unit with jurisdiction in the rural areas. However, Turkey responded with harsh military action after 1987. Starting from 1990 and 91, the Turkish Army (TAF) embraced a new doctrine "Cordon and Search" in which the PKK groups were caught in a big cordon and the perimeter was tightened through searches to engage and incapacitate armed militants via large-scale military operations (hereafter MOPs). ${ }^{122}$ With the support of land aviation units (Cobra helicopters), TAF's MOPs effectively disrupted PKK insurrection.

As seen in Figure 5, the aggregate level of violence - both the number of casualties (dashed trend line) and violent attacks (solid trend line) - indicates heightened violence from 1984 until 1993-94 (denoted with vertical dashed line). The trend in PKK-initiated attacks, as shown in Figure 6, reflects an increase until 1992 and then a decrease when Turkey launched large-scale and cross-border MOPs to win the territorial battle against 


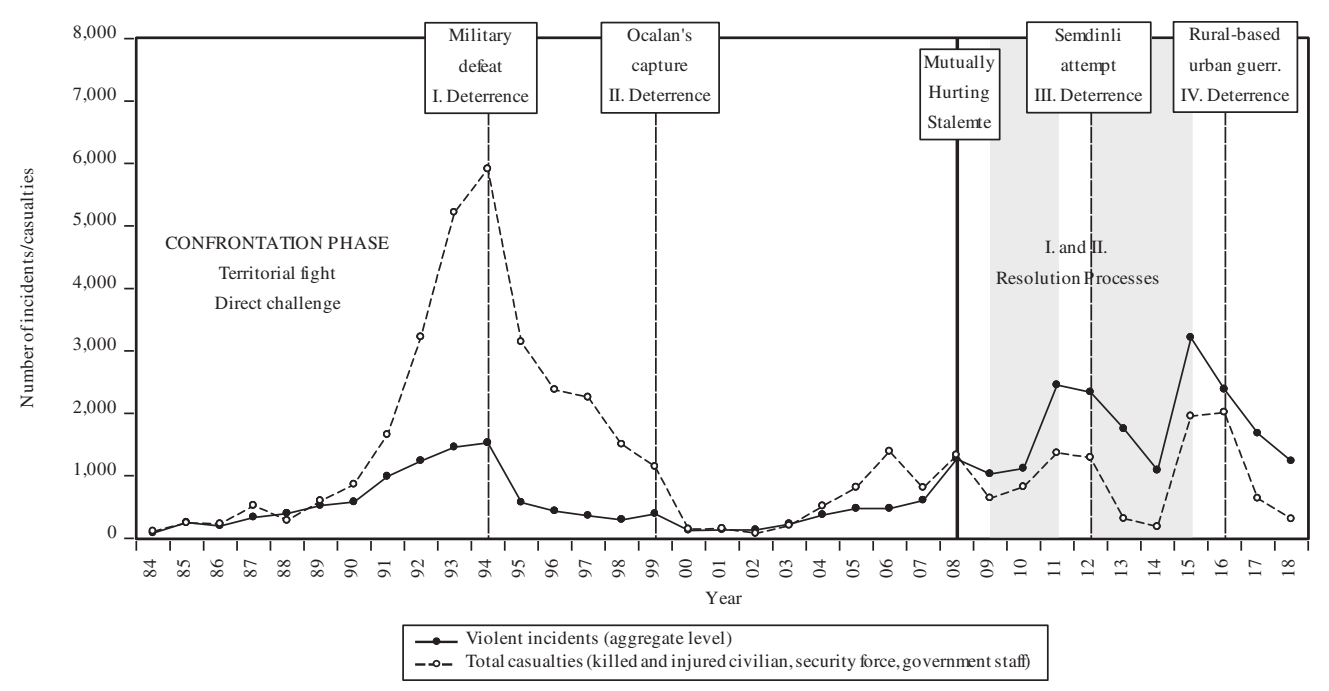

Figure 5. The number of aggregate violent incidents that resulted from both the PKK attacks and security force operations and resulting casualties (civilians, security forces and GKKs), 1984-2018.

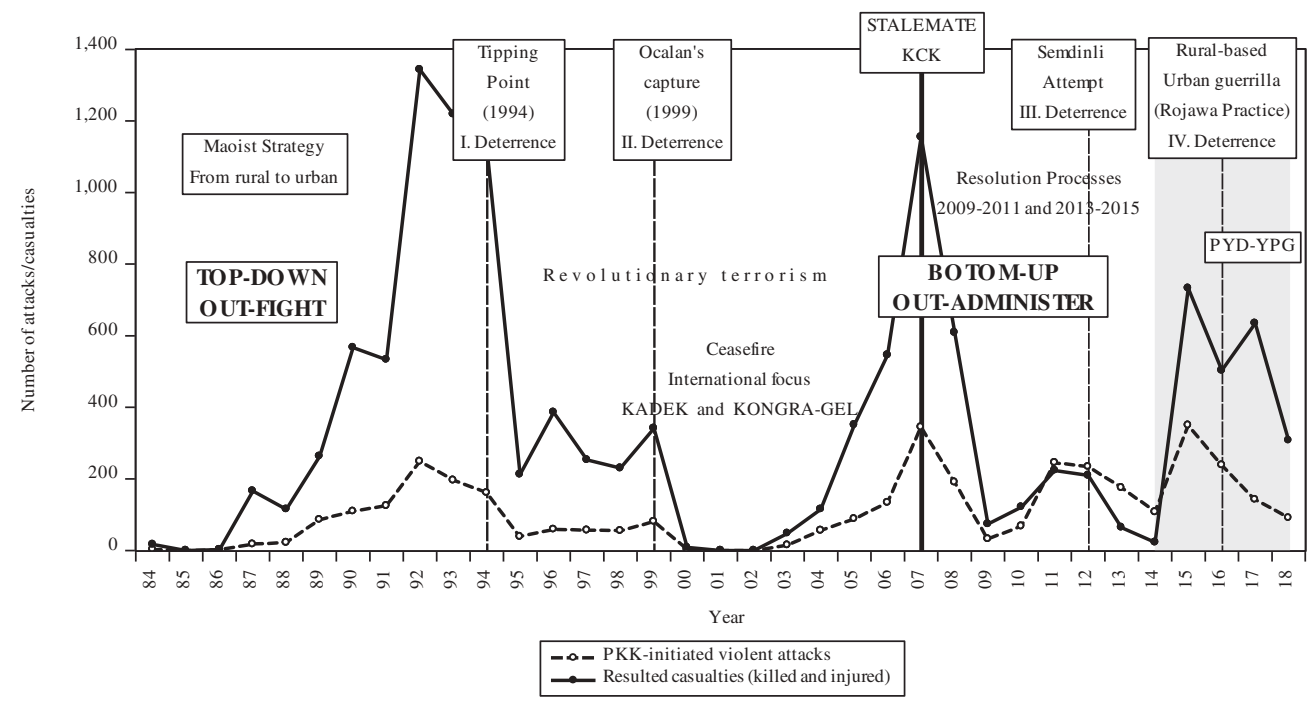

Figure 6. Number of PKK-initiated violent incidents only and resulting casualties (civilians, security forces and GKKs) 1984-2018.

the PKK. ${ }^{123}$ This trend is indicative of the lagged deterrent effect of the TAF's large-scale CT operations, whereby a new military doctrine ("cordon and search") and use of the land aviation units were initiated in the early 1990s.

As a result of Turkey's initial military deterrence effort, the PKK implicitly acknowledged its military defeat. ${ }^{124}$ Two statements from its founding leader, Abdullah Öcalan, serve as confirmation thereof. The first was made in a press conference held in Northern Iraq in $1993^{125}$; the second was issued in the pro-PKK periodical Serxwebun in 
April 1994. ${ }^{126}$ Öcalan-who believed in the use of force and had employed a Maoist strategy of a direct confrontational fight-declared that the military means are not the only solution ahead. He further stated that the PKK would need 50,000 guerillas to win, while the PKK only had 11,000-13,000 militants at the time. In both statements, Öcalan implied that the PKK forces were insufficient for a direct fight with TAF. So, the year 1993-1994 is marked as the initial and most influential deterrence impact on the PKK insurrection.

Having militarily defeated the PKK, Ankara mistakenly thought that such a deterrent impact on PKK violence would lead to its demise. Thus, they did not undertake any sociopolitical actions to transform the conflict into a nonviolent political dissent. There was only a weak and limited attempt by the then president Özal ${ }^{127}$ in 1993 . That did not go beyond Özal's individual entrepreneurship because military elites (then in power with tutelage) insisted on sole application of military deterrence to eradicate the PKK insurrection. The PKK then sealed the brake off of the process by killing thirty-three unarmed privates in the province of Bingöl in the same year. ${ }^{128}$

The period of 1993 and 1994 is a crucial milestone in evaluating the characteristics of the fight. The PKK gradually switched its strategy to negate Turkey's success in military deterrence in a direct fight. They shifted from conventional-style fighting supplemented by guerilla tactics to more 'asymmetric' means, such as terrorist attacks, in order to preserve its existence.

To identify the PKK's deviance from the Maoist three-stage theory, Figure 7 plots geographical locations of attacks in the southeastern region (where Turkey implemented emergency rule) and other regions. As seen in the figure, after 1994 the PKK's attacks in emergency rule areas and non-emergency rule areas slope toward each other, indicating a proportionate increase in PKK attacks in western cities. In short, to counterbalance

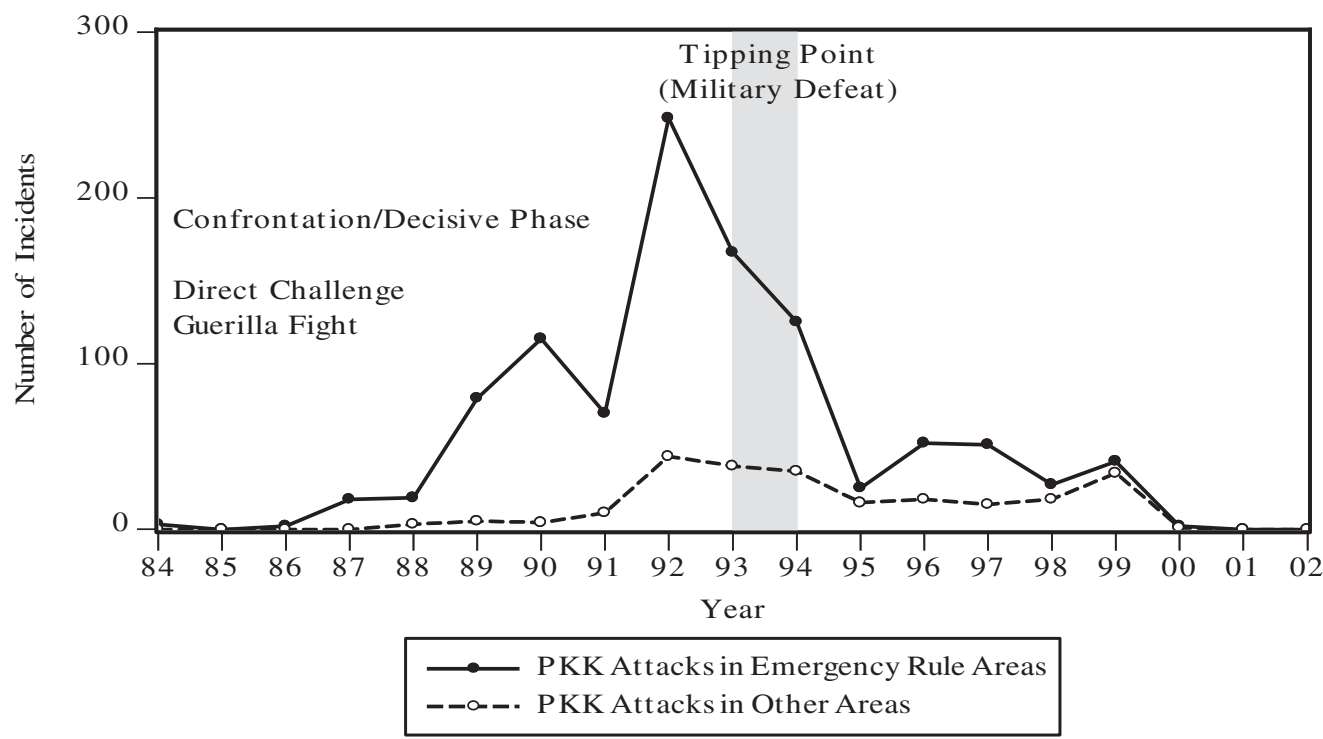

Figure 7. Location of violent incidents (both PKK-initiated MOPs) in emergency rule provinces (southeastern provinces) vs. non-emergency rule provinces (1984-2002). 
Turkey's heavy military deterrence, the PKK gradually shifted from capacity-oriented raids (physical attrition) and intimidation-oriented indiscriminate violence against the nonconforming Kurds (GKK members and their families) in southeastern and eastern provinces to will-oriented terror attacks for psychological attrition in Turkey's western provinces.

In the aforementioned regard, the first major deterrence impact led to a substitution effect from rural focused guerrilla attacks in the southeastern and eastern regions to terror attacks in western and urban areas. The PKK, as part of its strategy of expansion, not only conducted terror attacks in western areas but also strived to station into rural locations that are out of the Kurdish populated emergency rule region. With this, the PKK aimed to break the TAF's military deterrence effort that was underway in the emergency rule area, namely Turkey's south and southeastern regions. The reasoning behind it was to discredit the government's monopoly of violence and ability to protect its citizens. By going beyond the contested region, the TAF would have to be dispersed. The PKK has aimed at coercing Turkey into a political compromise through terrorism which would put a physical and a moral strain on both the government and the TAF, slowly eroding their will to fight. In other words, the PKK gradually started to rely on provocation and attrition rather than extermination. They shifted from a capacity-oriented strategy to a will-oriented one.

These all indicate that Turkey's successful application of initial military deterrence resulted in PKK's strategic shift. Direct challenges to security forces in the southeastern region were substituted with indirect and asymmetric targeting of civilians in western urban regions. In the Turkey-PKK conflict deterrence had a substituting/transferring effect. Thus, this particular conflict supports the claims of militant organizations diversifying when their existence is threatened ${ }^{129}$; repression of such groups might result in less favorable outcomes for the state ${ }^{130}$; and finally, deterrence results in a counterproductive $e^{131}$ zero-sum game. ${ }^{132}$

\section{Deterrent impact: capture of the founding leader, Öcalan}

Turkey adopted another deterrence measure in 1998 against Syria. Ankara used coercive diplomacy to create pressure on Syria by deploying troops to the Syrian border. The aim was to remove one of the long-lasting safe havens for the PKK and Öcalan in Syria. Ultimately, on October 20 1998, Turkey and Syria officials signed the "Adana Agreement" and the Syrian Government recognized the PKK as a terrorist organization and pledged to cease all aid and tolerance to the PKK. During this process Öcalan was expelled from Syria and captured by the Turkish forces in Nairobi, the capital of Kenya, and brought to Turkey in February 1999.

Öcalan's capture in 1999 yielded a dramatic decrease in the PKK-induced violence (see Figures 5 and 6). Upon Öcalan's call the PKK withdrew its militants and unilaterally abandoned all violence. However, the government did not capitalize on Öcalan's capture and its impact on the PKK; instead, it considered, again, how to eliminate the PKK. Turkey used the withdrawal as an opportunity for incapacitation that killed around 300 to 500 PKK militants. ${ }^{133}$

Subsequently, the PKK adapted and organizationally transformed itself twice: when it renounced violence in 2002 and was replaced with the Kurdistan Independence and Democracy Congress (KADEK), and then by rejecting violence as a means with the 
founding of the Kurdistan's People Congress (KONGRA-GEL) in $2003 .{ }^{134}$ In doing so, the PKK focused on the international arena, seeking political recognition as the legitimate representative of Turkey's Kurds. Despite PKK's legitimization and recognition efforts, the PKK was recognized as a terrorist organization in 2002 (and still is today) by certain countries and certain international organizations (e.g., the United States, Canada, the EU). Subsequently, when Öcelan's sentence changed from death to life imprisonment and his survival had been guaranteed, the PKK re-escalated its violent campaign., As Figure 6 illustrates, violence increased from 2003 to 2007 as the PKK struggled to sustain its power -both real and perceived-against Turkey. Shifting its attention from the international to the national domain, the PKK assumed a politico-military character with stronger social engagement and a political agenda. In 2007 it created the Democratic Union of Kurdistan $(\mathrm{KCK})^{135}$ as a part of a more precise political campaign to complement its guerilla and terrorist attacks with a strategic template designed to coerce Turkey into reaching a political compromise.

The changing dynamics of the conflict and the PKK were not only about the characteristics of violence. The PKK also shifted in their ideology and their goal. Despite that PKK had defined itself as a socialist liberation movement in its foundational manifesto and had embraced the Marxist-Leninist doctrine, the PKK adopted ethno-national views starting from early 1990s. More importantly, the PKK shifted in its goal as a result of the two deterrent effects and adapted itself to the new contingencies. In that, the previous main goal of the PKK, which was to establish an independent, socialist Kurdish state in the Middle East, including territories of southeastern Turkey, northern Iraq, Syria and Iran, got replaced with ideas of "Democratic Autonomy' and then 'Democratic Confederalism'”- a form of self-determination-as defined by Öcalan.

So, the second deterrent impact that came with Öcalan's capture yielded another substitution effect in which PKK transformed itself into a more politico and less military structure using violence more strategically by exploiting the very notion of asymmetrical warfare. Turkey's pursuit of a unilateral victory (that is, eradicating PKK) came to a halt when the state began to perceive the costly deadlock starting $2007 .{ }^{136}$ Against this background, Turkey - through back-channel talks with Öcalan on İmralı Island, where he has been incarcerated, and then, through track-two diplomacy with the PKK delegation in Oslo - has engaged in a conciliatory approach aimed at resolving the conflict through a negotiated settlement with the PKK.

The capturing of Öcalan, as a case study, adds to the literature on decapitation. His capture at first appears to be a successful deterrence strategy as the violence has been noticeably decreasing for the next few years. But the case of Öcalan's capture also shows that effective decapitation does not necessarily mean long-term success. Decapitation in cases of bigger, structured organizations, even when they have charismatic leaders, does not mean the end of the organization's existence. The organization will react by restructuring and transforming itself. Thus, for decapitation, to be most successful, it needs to be followed by appropriate political steps and means to secure a long-lasting peaceful period. Otherwise, when decapitation causes transformation, and not termination of an organization, the group will have time and opportunities to reboot itself.

After all, the deterrence strategies failed to bring the conflict into a halt and byunofficially-recognizing the stalemate, Turkey shifted to a conciliatory approach and employed its first resolution attempt. The most common explanation of why states 
embrace a conciliatory approach in their struggle against a violent non-state actor is a military stalemate between conflicting parties. ${ }^{137}$ In most cases of asymmetrical conflicts, violence brings parties into a painful stalemate, as has happened in the Turkish case. In a stalemate parties reevaluate their situation, role, and strength in the conflict and start seeking reconciliation and resolution through dialogue and negotiation. ${ }^{138}$ Turkey's recognition of the hurting stalemate, as verified by the VAR results, is one of the main reasons for its changing approach from a sole military deterrence to conciliation. That brought Turkey's first resolution attempt named "the Kurdish Opening" in 2009.

\section{Deterrent impact: "Şemdinli" attempt}

The Kurdish Opening was crippled in 2011 due to a variety of reasons that are beyond this study's scope. ${ }^{139}$ The violence measures show re-escalation, as indicated in both the aggregate level violence in Figure 5 and the PKK-initiated violence in Figure 6 . Thereafter, the PKK employed another symbolic attempt for territorial control in the region. Intense fighting occurred in the days between 8-19 September 2012 (Figure 5), when PKK struggled for control of the Şemdinli area of the province of Hakkari. As part of its military deterrence effort, the TAF shifted in its COIN doctrine: from cordon and search to "search-find-destroy" starting from 2010. In this period, the TAF switched from large-scale to small-scale military operations, with fewer and more professional military units, with more rapid deployment via air cavalry operations and with a higher response rate for targeted killings. As a result of its new operational concept, the TAF incapacitated 137 PKK rebels in eleven days, while six soldiers and two GKK members were killed. As a result of this operation, the PKK's Şemdinli attempt was abandoned with high casualties. The PKK kept territorial control of the Şemdinli region only in their rhetoric. ${ }^{140}$

While the TAF's Şemdinli operation can be considered another important deterrent impact, PKK violence after 2012 decreased (see Figures 5 and 6) mainly because of the second round of the resolution attempt later that year. Turkey received a direct message from Öcalan to officially start a peace process in Diyarbakır province upon the Nevruz festivities. However, the second peace attempt was similarly crippled as the first one. On July 22, 2015 the region's due to high instability, the effects of the neighboring Syrian civil war on Turkey's security concerns, the PKK's spoiling attacks (killing two policemen in their home in Şanlıurfa/Suruç), domestic political dynamics (the AKP's loss of its parliamentary majority in the June 2015 elections), and more led to the fracturing of the latest resolution process. Turkey was back to its intense securitization strategy along with a harsh anti-PKK state discourse, yielding high tensions and escalating violence as shown in Figures 5 and 6 . The new wave of clashes between Turkey and the PKK occurred in a new setting; that is, the PKK shifted the fight from the rural to urban realm and from the physical to human terrain. Hence, the second failure of the peace process brought about a deeper break. Between mid-July 2015 and March 2016, security forces' casualties reached 355 (265 soldiers, 133 police, and seven GKKs), while 285 civilians lost their lives (civilian casualties include attacks by the Islamic State). ${ }^{141}$ As a result of security operations, government officials claimed that 3,583 PKK members were incapacitated, while another 602 were captured and 574 surrendered in one year (until June 17, 2016). ${ }^{142}$ According to the International Crisis Group's open source database, the figure for 
incapacitated PKK members since July 202015 (until July 4, 2018) is 2,150, for civilian casualties is 452 , and for the security force casualties is $1,092 .{ }^{143}$

In its then new strategy, "rural-based urban guerilla warfare"-which was also the title of a book by one of the PKK's top council members, Duran Kalkan-the PKK started to employ lessons learned from its Syrian branch (PYD) in the fight against the Islamic State (IS). In their struggle to eradicate IS from Rojava-a territory in Northern Syria-the PYD has accumulated a great amount of urban warfare experience. According to this model, the PKK dug ditches and built barricades as part of their overall strategy of "selfgovernance" in Kurdish-populated towns (e.g., Şırnak-Cizre, Diyarbakır-Sur and Silvan, Mardin-Nusaybin, Hakkari-Yüksekova). As plotted in Figure 8, the dashed line denoting attacks in urban areas far exceeds attacks in rural areas, clearly showing the trend toward the urbanization of PKK violence during this new period of the conflict (shaded area). The incident type in PKK attacks shows a similar trend as plotted in Figure 9, where a dashed line denoting the use of explosive devices (less confrontation) exceeds armed attacks in the same period.

\section{Deterrent impact: UAVs and targeted killing-decapitation}

In the second half of 2018 Turkey, for the first time in its prolonged CT struggle against the PKK, realized decapitation/targeted killings of high-profile PKK leaders both inside Turkey and abroad. With the increased use of high-tech kinetic capabilities, particularly armed drones, Turkey engaged in a campaign of targeted killings of prominent PKK figures. The recent sensational targeted killing of a senior PKK figures (e.g., Ismail Ozden, Zaki Shingali, Atakan Mahir) is important to exemplify Turkey's latest capacity with the Unmanned Aerial Vehicle (UAV) based surgical airstrike. In that, a senior PKK figure, Ismail Ozden-code-named "Uncle" Zaki Shingali-was killed in the northern Iraqi town of Sinjar nearly $130 \mathrm{~km}$ away from Turkey's border by UAVs and F-16s. Ozden was the first high-profile PKK leader on Turkey's "most-wanted terrorists" list who was killed in

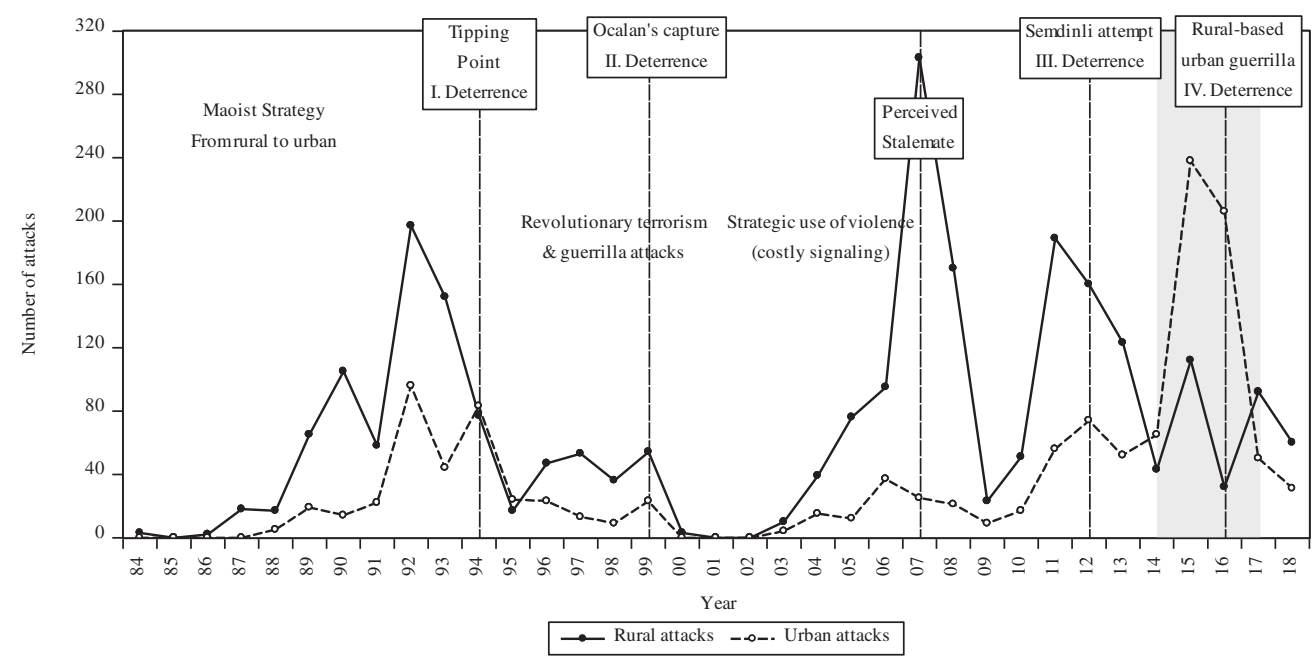

Figure 8. Number of PKK-initiated attacks (only) in rural versus urban areas (1984-2018). 


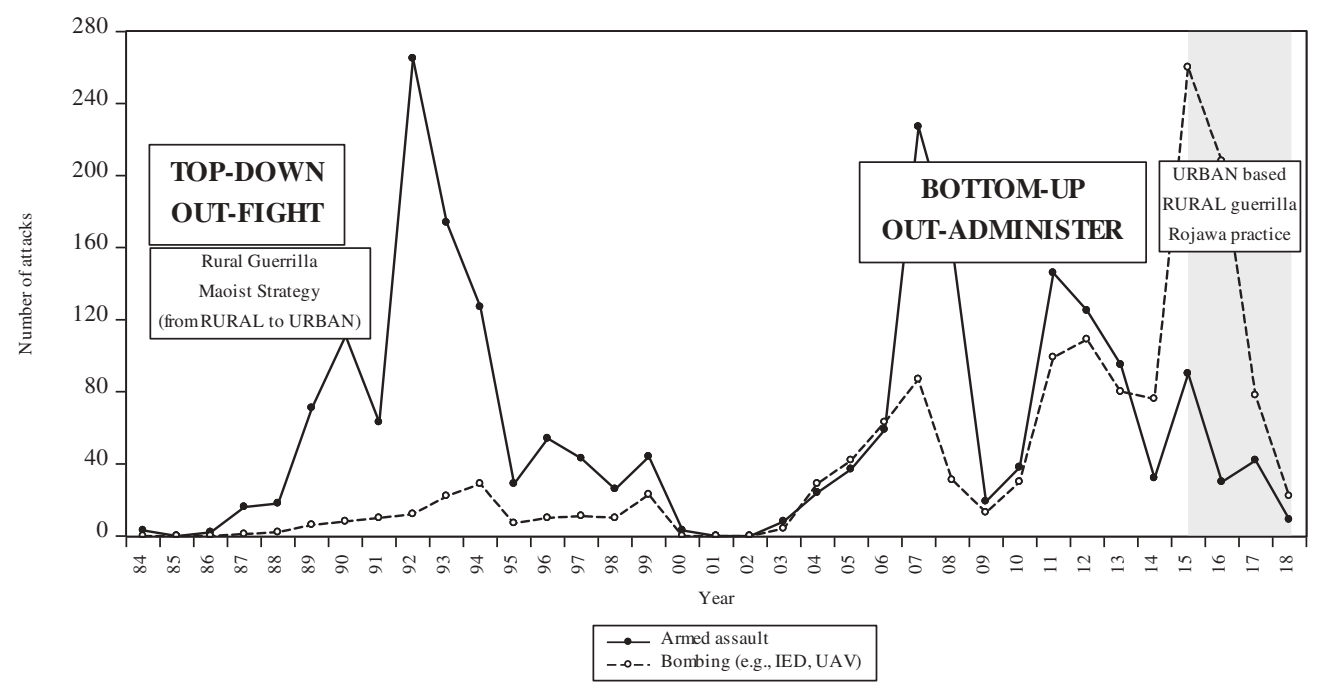

Figure 9. PKK-initiated armed attacks versus bombings (1984-2018).

the first "targeted killing" type of operation abroad. Targeted killing using multi-category intelligence (i.e., HUMINT and SIGINT) technically aligned with airstrike capabilities and real time intelligence turned out strategically effective and sensational in limiting PKK's mobility in and out of Turkey's borders. Thus, it can be assumed that in the years to come, Turkey will lean more on similar strategies supported by drone-oriented attacks.

In the latest period, however, the conflict has reflected significant changes in its nature and character that should be taken into consideration in terms of Turkey's military deterrence efforts in its CT campaign. First, the once intra-state characteristic of Turkey's conflict has become more dependent on regional developments particularly brought by the Syrian civil war (2011-present) and the increasing role of the PKKaffiliated PYD as well as the Kurdish fighters of the People's Protection Units (YPG) in Syria, further perplexing the already complex setting.

The PYD, a long-standing branch of the PKK, has acquired the control of northern Syria with support, both politically and militarily, from the U.S., in its fight against ISIS. The PYD has gained international recognition and legitimacy. This new development in northern Syria has allowed the PKK to gain a territorial insurgent character due to the PYD's quasi-state control over Syria's bordering Rojava region. Moreover, the PYD's international de facto legitimacy, due to its fight against IS, seems to continue to protect a quasi-legitimate and quasi-governed safe haven for the PKK, making the PKK a territorial organization. This is a crucial development, as Rojava now serves as an important logistical base for weapons, ammunition, recruitment, and training. All of this will help sustain PKK's insurgent and terrorist activities and add more complexities to Turkey's already complex domestic and regional security situation. Therefore, the eruption of the Arab Spring in 2010 and the subsequent regional developments have dramatically changed the nature of the Turkey-PKK conflict, rendering it a territorially regionalized and politically internationalized issue. In this regard, a domestic military deterrence campaign against the PKK, disregarding the socio-political context, will 
probably be even less relevant and effective in the future. However, it should also be noted that Turkey started to employ a more effect-based strategy against the PYD and ISIS and wanted to show its strategic capacity and political will by conducting a cross-border operations, e.g., Operation Euphrates Shield on August 24, 2016, Operation Olive Branch on January 2018-April 2018, and Operation Peace Spring started on October 9, 2019.

\section{Overall results of incapacitation}

Overall, when looking at the entire span of the conflict and total figures, the Turkish security forces incapacitated a large number of PKK militants. Between August 1984, when the violent campaign officially started, and in 2018, 34,128 PKK militants were either killed and/or injured, while another 8,102 were captured. A total of 42,230 PKK militants were incapacitated $^{144}$ during the period between 1984 and 2018. In his defense of the Turkish army's long effort and condemnation of respective governments and politicians' failure to take relevant socio-economic and political actions, the former Turkish Army Chief of General Staff İlker Başbuğ pointed out that these figures indicate that the PKK's entire force of 5,000-7,000 militants had been totally incapacitated five to six times over, ${ }^{145}$ implying that incapacitation-oriented, eliminationist efforts without grand strategic-level political results were inconclusive.

Whether analyzing trends in violence solely induced by the PKK or the aggregate-level violence resulting from both military/security force operations and PKK attacks, all indicators show that violence levels went back up after the PKK's longest ceasefire ended in 2003. Figures 5 and 6 reflect the swift uptick in violence in 2003-2007 and in 2015, contrasting the steadily declining trend since the PKK's military defeat in the mid-1990s. The growing violence levels indicate the effectiveness of asymmetrical warfare employed by the PKK.

The incapacitation figures for 1984-2000 and 2000-2018 periods indicate another difference between the more conventional and asymmetrical warfare. The incapacitation trend, as plotted in Figure 10, shows that the bulk of the incapacitation (72.56 percent) occurred within the decisive period before Öcalan's capture. In that period the PKK sought a unilateral military victory in a "direct" fight targeting Turkey's capacity to fight. Likewise, casualties in the ranks of security forces reflect similar results. Seventytwo percent of the losses occurred during the 1984-2000 period. Despite the steep increase in the number of violent incidents (as depicted in Figures 5 and 6), Figure 10 shows that the casualty levels for both sides have been lower since the character of the conflict has changed, using violence symbolically and in a more asymmetrical nature.

\section{Conclusion}

This study has analyzed the impact and effectiveness of Turkey's military deterrence effort in its struggle against the PKK in the conflict's entire span. Results from VAR analyses indicate that in contrast with the motto Turkey's incapacitation efforts did not reduce PKK violence in the overall sense. What is more, they yielded a counterproductive impact. That is, the PKKinduced violence has not been reduced by killing, injuring, and capturing the armed PKK militants in the period between May 1994 and December 2018, in which the PKK has been pursuing political compromise by employing indirect means and asymmetry. 


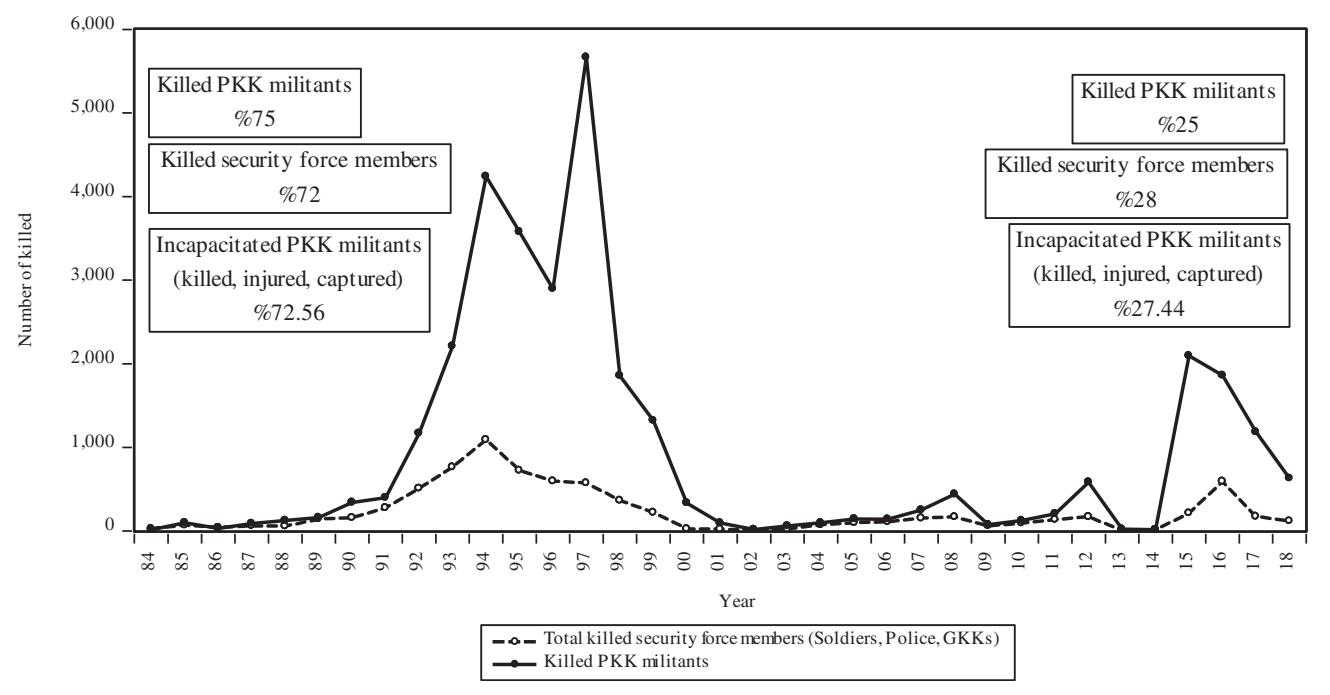

Figure 10. Rate of incapacitated PKK militants and security force casualties.

Longitudinal analysis (1984-2018) indicates that Turkey's deterrence efforts induced important (mid-term) deterrent impacts on PKK violence. They resulted in the PKK's change of its grandeur goal (from secession to autonomy), a revision in its ideology from pure socialism to embracing nationalist views, and a shift in the form and characteristics of violence. Hence, from a purely military perspective, the incapacitation effort yielded partial successes in certain periods; however, the Turkish state's inability to convert military success into a political one was one of the prime reasons that this approach failed to achieve the state's objectives.

As the case of the PKK conflict yields, deterrence has a short-term deterrent effect until the inferior innovate into other tactical means. If the insurgents' shift in the grand strategic and operational levels is taken as a teaching moment, deterrence can, nonetheless, have longer effects. States' strategies against terrorist organizations and/or insurgencies should not aim to rack up a headcount. Deterrence should be used when it is both politically and strategically viable-rather than as a stand-alone solution. In that, states should employ deterrence as a strategic tool in the context of the "diplomacy of war" within their grand bargaining game. ${ }^{146}$ Deterrence should be used in an acquisitive sense rather than through a punitive and symbolic effort, which damages the state's perceived legitimacy and yields counterproductive. ${ }^{147}$

Within this context, states' grand strategy should incorporate a meaningful political end result for the conflicting parties in which the conflict is to be transformed into a nonviolent dissent first and then into a sustainable peace. This is because, as Howard -in consensus with Schelling-puts it, military victories and militarily incurred deterrence do not determine the outcome of the conflict, but they do provide political opportunities to end it. ${ }^{148}$

As evident with the escalated violence after incurred deterrence impacts, Turkey's military deterrence approach, in the long run, resulted in a substitution effect rather than a deterrent one, in all but the latest period. Present conditions clearly show that throughout the PKK struggle the state has not used incapacitation as a meaningful and 
sufficient tool to terminate or transform the conflict. Securitization and incapacitation efforts might have helped in generating a deterrent impact in certain periods of the conflict - particularly in the decisive/confrontation phase. Otherwise these efforts were counterproductive due to the lack of a viable grand strategy and political end-state tied to these military efforts.

What is significant about Turkey's latest military deterrence policy is that Turkey, for the first time since its long-term struggle against the PKK, used effect-based approach to its deterrence effort via military action seeking strategic effect. However, what has not changed is the approach limited to short-term regional contingencies lacking a feasible, visionary and long-sighted political end-state(s). New weapons and techniques used by the state on the front lines are bound to give rise to new maneuvers and tactical evolutions by its non-state adversaries - as well as a reversion to old tactics. Yet, the dynamic structure in the ongoing Syrian civil war and the delicate balance between the global powers and their local partners and proxies indicate the importance of pursuing deterrence for strategic effects rather than sole incapacitation of PKK and/or YPG militants. Turkey's CT efforts vis-à-vis the PKK are now part of its foreign policy. Given the complexities and multitude of actors, both state and non-state, involved in the proxy war in Syria, Turkey's deterrence approach should move far beyond a mere application of eliminationist efforts and should be tied to a grand strategic political level end-state aligned with Turkey's sustainable foreign policy vision in the region as Turkey partly attempted with its latest effect-based operations.

\section{Notes}

1. See for instance, Richard K. Betts, "The soft underbelly of American primacy: Tactical advantages of terror," Political Science Quarterly 117, no. 1 (2002): 19-37; Paul K. Davis, and Brian Michael Jenkins, Deterrence and Influence in Counterterrorism: A Component in the War on al Qaeda. (Santa Monica, CA: Rand Corporation, 2002); Bruno S. Frey, Dealing with Terrorism - Stick or Carrot? (Cheltenham, UK: Edward Elgar Publishing, 2004); Bruno S. Frey and Simon Luechinger, "How to Fight Terrorism: Alternatives to Deterrence," Defense and Peace Economics 14, no. 4 (2003): 237-49; Walter Enders and Todd Sandler. "The Effectiveness of Antiterrorism Policies: A Vector-Autoregression-Intervention Analysis," American Political Science Review 87, no. 4 (1993): 829-44.

2. See for instance, William M. Landes, "An Economic Study of U.S. Aircraft Hijacking 1961-76," Journal of Law and Economics 21 (1978): 1-32.; Prunckun Jr, Henry W., and Philip B. Mohr. "Military deterrence of international terrorism: An evaluation of Operation El Dorado Canyon," Studies in Conflict \& Terrorism 20, no. 3 (1997): 267-280; Dugan, Laura, Gary LaFree, and Alex R. Piquero. "Testing a rational choice model of airline hijackings," Criminology 43, no. 4 (2005): 1031-1065.; Enders, Walter, and Todd Sandler. "Transnational terrorism in the post-Cold War era," International Studies Quarterly 43, no. 1 (1999): 145-67.

3. See for instance, Elli Lieberman, ed. Deterring terrorism: A model for strategic deterrence. Routledge, 2018; Robert F. Trager, and Dessislava P. Zagorcheva. "Deterring terrorism: It can be done," International Security 30, no. 3 (2006): 87-123.

4. Richard Shultz, "Coercive Force and Military Strategy: Deterrence Logic and the CostBenefit Model of Counterinsurgency Warfare," Western Political Quarterly 32, no. 4 (1979): 444-66; Austin T. Turk, "Confronting Enemies Foreign and Domestic: An American Dilemma?," Criminology \& Public Policy 1, no. 3 (2002): 345-50; Mustafa Cosar, "The dichotomy in the perception, conception and the response to terrorism: the case of the PKK," Counter Terrorism in Diverse Communities 90, no. 2011 (2011): 268.; John 
Bradford Braithwaite, "Thinking Critically About the War Model and the Criminal Justice Model for Combating Terrorism," SSRN Electronic Journal, 2002; Mustafa Cosar Ünal, "Counterterrorism in Turkey": Policy choices and policy effects toward the Kurdistan workers' party (PKK). Routledge, 2012.

5. Kemal Kirisci, and Gareth M. Winrow. The Kurdish question and Turkey: An example of a trans-state ethnic conflict (Oxon, UK: Routledge, 2013), 7-8; Mustafa Coşar Ünal, "Counterterrorism in Turkey": Policy Choices and Policy Effects Toward the Kurdistan Workers' Party (PKK) (Oxon, UK: Routledge, 2012).

6. Detailed casualty figures are provided in Appendix-A (Table A-1).

7. Andrew H. Kydd, and Barbara F. Walter. "The strategies of terrorism," International security 31, no. 1 (2006): 49-80.

8. Mustafa Cosar Unal. "Strategist or Pragmatist: A Challenging Look at Ocalan's Retrospective Classification and Definition of PKK's Strategic Periods Between 1973 and 2012," Terrorism and Political Violence 26, no. 3 (2014): 420-22.

9. Ünal, "Is It Ripe Yet?"

10. Metin Gürcan and Mustafa Coşar Ünal, "Reaching a balance of resolve: the enduring conflict between Turkey and the PKK," In Deterring Terrorism (Routledge, 2018), 193-230.

11. Ersel Aydinli. "Between security and liberalization: Decoding Turkey's struggle with the PKK," Security Dialogue 33, no. 2 (2002): 220-22; Ünal, Counterterrorism in Turkey, 3.

12. The PKK declared a number of unilateral ceasefires for various reasons, but Turkey did not respond to them in order not to legitimize the PKK, except for a de facto situational armistice for certain periods during the resolution process. For more details see Ünal, Mustafa Cosar, "Counterinsurgency and Military Strategy: An Analysis of the Turkish Army's COIN Strategies/Doctrines," Military Operations Research 21, no. 1 (2016): 55-88.

13. E.g., Hurriyet News "Until No terrorist remains" accessed on 15 December 2018, available at http://www.hurriyet.com.tr/tumgeneral-tarakci-son-terorist-kalana-kadar-m-40576932.

14. Güneş Murat Tezcür. "When democratization radicalizes: The Kurdish nationalist movement in Turkey," Journal of Peace Research 47, no. 6 (2010): 775-89.

15. See for instance, Tarik Eser, "The Impact of the Turkish Policies and Actions Toward the PKK Terrorist Organization: A Time Series Analysis" (Ph.D. Dissertation, Sam Houston State University, Texas, 2007).

16. See Enders and Sandler, 'The Effectiveness of Antiterrorism Policies'. Brandt, Patrick T., and Todd Sandler. “A Bayesian Poisson vector autoregression model," Political Analysis 20, no. 3 (2012): 292-315; Carlos Pestana Barros, José Passos, and Luis A. Gil-Alana. "The timing of ETA terrorist attacks," Journal of Policy Modeling 28, no. 3 (2006): 335-346; Carlos Pestana Barros, "An intervention analysis of terrorism: The Spanish ETA case," Defence and Peace Economics 14, no. 6 (2003): 401-412; and Syed Ali Raza, and Syed Tehseen Jawaid. "Terrorism and tourism: A conjunction and ramification in Pakistan," Economic Modelling 33 (2013): 65-70.

17. See for instance, Bahar Araz-Takay, K. Peren Arin, and Tolga Omay, "The endogenous and non-linear relationship between terrorism and economic performance: Turkish evidence," Defence and Peace Economics 20, no. 1 (2009): 1-10; Mete Feridun, and Muhammad Shahbaz, "Fighting terrorism: are military measures effective? Empirical evidence from Turkey," Defence and Peace Economics 21, no. 2 (2010): 193-205; Pinar. Derin-Güre, "Separatist Terrorism and the Economic Conditions in South-Eastern Turkey," Defence and Peace Economics 22, no. 4 (2011): 393-407.

18. Ünal, The dichotomy in the perception.

19. Ünal, Counterterrorism in Turkey.

20. Arie W. Kruglanski, Crenshaw, Martha, Post, Jerrold M., and Victoroff, Jeff. "What should this fight be called? Metaphors of counterterrorism and their implications," Psychological Science in the Public Interest 8, no. 3 (2007): 97-133.

21. Ünal, "Counterinsurgency and Military Strategy". 
22. Marina Miron, "First-Party COIN: Approaches of Choice in Peru, Turkey and Sri Lanka in Strategic Perspective" (Ph.D. Dissertation, University of New South Wales, Kensington, 2018).

23. Doron Almog, "Cumulative deterrence and the war on terrorism," Parameters 34, no. 4 (2004): 4-19.

24. Classical deterrence theory that had emerged in the Cold War era is not applicable in the contemporary COIN campaigns.

25. Almog, "Cumulative deterrence," 9.

26. Ibid.

27. Marina Miron, 2019. "On Irregular Wars, Insurgencies and How to Counter Them: Enemy and Population-centric Approaches in Comparative Perspective," Revista Científica General José María Córdova 17 (27): 457-480.

28. Ibid.

29. Lafree Dugan, and Piquero, "Testing a Rational Choice Model"; Frey, Dealing with Terrorism; Frey and Luechinger, "How to Fight Terrorism"; Landes, "An Economic Study of US Aircraft Hijacking 1961-76"; Enders and Sandler, "The Effectiveness of Antiterrorism Policies"; Ünal, "The Dichotomy."

30. Enders and Sandler, "The Effectiveness of Antiterrorism Policies"; Michael Kenney, From Pablo to Osama (University Park, PA: Pennsylvania State University Press, 2007), 56; Jeffrey Ian Ross, "Structural causes of oppositional political terrorism: Towards a causal model," Journal of Peace Research 30, no. 3 (1993): 317-329; Lafree Dugan, and Piquero, "Testing a Rational Choice Model"; Frey and Luechinger, "How to Fight Terrorism."

31. Lafree Dugan, and Piquero, "Testing a Rational Choice Model"; Enders and Sandler, "The Effectiveness of Antiterrorism Policies."

32. Frey and Luechinger, "How to Fight Terrorism".

33. Mendes, "Certainty, Severity"; Kenney, "From Pablo to Osama".

34. Frey, Dealing with Terrorism.

35. Braithwaite, "Thinking Critically"; Lawrence W. Sherman, "Defiance, deterrence, and irrelevance: A theory of the criminal sanction," Journal of research in Crime and Delinquency 30, no. 4 (1993): 445-473.

36. Tyler, "Multiculturalsm"; Tom R. Tyler, "Multiculturalism and the Willingness of Citizens to Defer to Law and to Legal Authorities," Law \& Social Inquiry 25, no. 4 (2000): 983-1019; Sherman, "Defiance, Deterrence, and Irrelevance."

37. Martha Crenshaw, "How Terrorism Ends" (US Institute of Peace, Washington, DC, 1999): 9.

38. Braithwaite, "Thinking Critically".

39. Martha Crenshaw, ed., Terrorism in context (University Park, PA: Pennsylvania State University Press, 2010); Paul Wilkinson, Terrorism Versus Democracy: The Liberal State Response (Oxon, UK: Routledge, 2006.

40. Shultz, "Coercive Force and Military Strategy"; Turk, "Confronting Enemies Foreign and Domestic"; Crenshaw, "How Terrorism Ends"; Frey and Luechinger, "How to Fight Terrorism"; Mark Irving Lichbach, "Deterrence or escalation? The puzzle of aggregate studies of repression and dissent," Journal of Conflict Resolution 31, no. 2 (1987): 266-97; John A. Nevin, "Retaliating against terrorists," Behavior and social issues 12, no. 2 (2003): $109-28$.

41. Daniel Byman, "The logic of ethnic terrorism," Studies in Conflict \& Terrorism 21, no. 2 (1998): 149-69.

42. Landes, "An Economic Study of US Aircraft Hijacking 1961-76"; Prunckun Jr. and Mohr, "Military Deterrence of International Terrorism"; Dugan, Lafree, and Piquero, "Testing a Rational Choice Model"; Enders and Sandler, "Transnational Terrorism in the PostCold War Era."

43. Lee E. Dutter, and Ofira Seliktar, "To martyr or not to martyr: Jihad is the question, what policy is the answer?" Studies in Conflict \& Terrorism 30, no. 5 (2007): 429-43.; 2: Michele L. Malvesti, "Bombing bin Laden: Assessing the effectiveness of air strikes as a counterterrorism strategy," Fletcher F. World Aff. 26 (2002): 17. 
44. Frey and Luechinger, "How to Fight Terrorism"; Lichbach, "Deterrence or Escalation?"; Nevin, "Retaliating."

45. Robert F. Trager, and Dessislava P. Zagorcheva, "Deterring terrorism: It can be done," 89.

46. Richard K. Betts, "The soft underbelly of American primacy."

47. Gregory D. Miller, "Terrorist decision making and the deterrence problem," Studies in Conflict \& Terrorism 36, no. 2 (2013): 132.

48. Ibid., 135.

49. Ibid., 145.

50. Dugan, Laura, and Erica Chenoweth. "Moving beyond deterrence: The effectiveness of raising the expected utility of abstaining from terrorism in Israel," American Sociological Review 77, no. 4 (2012): 597-624.

51. Almog, "Cumulative deterrence and the war on terrorism," 15.

52. Paul K. Davis, and Brian Michael Jenkins, "A System Approach to Deterring and Influencing Terrorists," Conflict Management and Peace Science 21, no. 1 (2004): 3-15.

53. Boaz Ganor, "Terrorist organization typologies and the probability of a boomerang effect," Studies in Conflict \& Terrorism 31, no. 4 (2008): 56.

54. Michael C. Horowitz, Evan Perkoski, and Philip BK Potter. "Tactical Diversity in Militant Violence," International Organization 72, no. 1 (2018): 140.

55. Laure Paquette, Terrorist-Insurgent Thinking and Joint Special Operational Planning Doctrine and Procedures (Macdill Fl: JSOU, 2010).

56. Perkoski and Potter, "Tactical Diversity in Militant Violence," 143-4.

57. Paul J. DiMaggio, and Walter W. Powell, "The Iron Cage Revisited: Institutional Isomorphism and Collective Rationality in Organizational Fields," American Sociological Review, 48/2 (1983): 147-60; Daniel A. Levinthal, "Organizational adaptation and environmental selection-interrelated processes of change," Organization Science 2, no. 1 (1991): 140-45; Barry R. Posen, "Nationalism, the mass army, and military power," International Security 18, no. 2 (1993): 80-124.

58. Emanuel Adler, "Complex Deterrence in the Asymmetric-Warfare Era," Complex Deterrence: Strategy in the Global Age (2009): 85-108; Ivan Arreguín-Toft, "Unconventional deterrence: How the weak deter the strong," Paul, Morgan, and Wirtz, Complex Deterrence (2009), 204; Malka, Amos. "Israel and asymmetrical deterrence." Comparative Strategy 27, no. 1 (2008): 15.

59. Frey, Dealing with Terrorism; Frey and Luechinger, "How to Fight Terrorism."

60. Turk, "Confronting Enemies Foreign and Domestic"; Braithwaite, "Thinking Critically"; Frey, Dealing with Terrorism; Nevin, "Retaliating."

61. Wilkinson, Terrorism versus Democracy.

62. Gary L. Geipel, "Urban Terrorists in Continental Europe after 1970: Implications for Deterrence and Defeat of Violent Nonstate Actors," Comparative Strategy 26, no. 5 (December 13, 2007): 439-67.

63. Brian M. Jenkins, "Should Our Arsenal Against Terrorism Include Assassination" (No. P7303, Rand Corp., Santa Monica CA, 1987); Jones, Seth G. "Fighting networked terrorist groups: Lessons from Israel," Studies in Conflict \& Terrorism 30, no. 4 (2007): 281-302.

64. Matt Frankel, "The ABCs of HVT: Key lessons from high value targeting campaigns against insurgents and terrorists." Studies in Conflict \& Terrorism 34, no. 1 (2010): 17-30.

65. Audrey Kurth Cronin, "How al-Qaida ends: The decline and demise of terrorist groups," International Security 31, no. 1 (2006): 7-48.

66. Jenkins, Should Our Arsenal Against Terrorism Include Assassination.

67. Jenna Jordan, "When heads roll: Assessing the effectiveness of leadership decapitation," Security Studies 18, no. 4 (2009): 719-55.

68. Jenna Jordan, "Attacking the Leader, Missing the Mark: Why Terrorist Groups Survive Decapitation Strikes," International Security 38, no. 4 (April 2014): 20.

69. Aaron Mannes, "Testing the snake head strategy: Does killing or capturing its leaders reduce a terrorist group's activity?" The Journal of International Policy Solutions 9 (2008). 
70. Patrick B. Johnston, "Does Decapitation Work? Assessing the Effectiveness of Leadership Targeting in Counterinsurgency Campaigns," International Security 36, no. 4 (April 2012): 47-79.

71. Bryan C. Price, "Targeting Top Terrorists: How Leadership Decapitation Contributes to Counterterrorism," International Security 36, no. 4 (April 2012): 9-46.

72. Ibid., 43-4.

73. Cauley and Im, "Intervention Policy Analysis of Skyjackings and Other Terrorist Incidents"; Enders and Sandler, "The Effectiveness of Antiterrorism Policies."

74. Wenger and Wilner, Deterring Terrorism, 302.

75. Thomas C. Schelling, "Arms and influence" in Strategic Studies, edited by Thomas G. Mahnken and Joseph A. Maiolo, 2nd ed. (Oxon, UK: Routledge, 2008), 96-114.

76. Crenshaw, Terrorism in Context; Turk, "Confronting Enemies Foreign and Domestic"; Braithwaite, "Thinking Critically"; Lichbach, "Deterrence or Escalation?"; Nevin, "Retaliating".

77. Frey, Dealing with Terrorism; Turk, "Confronting Enemies Foreign and Domestic."

78. Shultz, "Coercive Force and Military Strategy"; Frey, Dealing with Terrorism; Crenshaw, "How Terrorism Ends"; Frey and Luechinger, "How to Fight Terrorism"; Nevin, "Retaliating."

79. Wenger and Wilner, Deterring Terrorism.

80. Frey, Dealing with Terrorism.

81. Ünal, Counterterrorism in Turkey, 163-67.

82. Uprooting these people from their original habitat is a fragile policy choice with many complications and ramifications and only its relation to the logic of deterrence is discussed here. Yet, moral rectitude of such policy is beyond this study's scope.

83. Mustafa Coşar Ünal, "Terrorism versus insurgency: a conceptual analysis," Crime, Law and Social Change 66, no. 1 (2016): 21-57.

84. Kilcullen describes this approach as "enemy-centric counterinsurgency" in Turkey's official discourses; however, it is more generally referred to as "counterterrorism." See Kilcullen, 'Two Schools'.

85. Nevruz (newroz in original) is a traditional holiday for Kurds and certain other populations denoting arrival of spring.

86. Kemal Kirişçi, “The Kurdish Issue in Turkey: Limits of European Union Reform," South European Society and Politics 16, no. 2 (2011): 335-349.

87. Mary Lou O'Neil, "Linguistic Human Rights and the Rights of Kurds" in Human Rights in Turkey, edited by Zehra F. Kabasakal Arat, (Philadelphia, PA: University of Pennsylvania Press, 2007): 72-86.

88. Mustafa Cosar Unal, "Opening a door for return to home: impact and effectiveness of Turkish repentance laws," Studies in Conflict \& Terrorism 39, no. 2 (2016): 128-164.

89. Aydınl, "Between Security and Liberalization," 210-22; Ünal, "Terrorism versus Insurgency".

90. Özlem Kayhan Pusane, “Turkey's Kurdish opening: Long awaited achievements and failed expectations," Turkish Studies 15, no. 1 (2014): 81.

91. Turkish official discourse toward the PKK has always been in the frame of counterterrorism. Please see Ünal, "Terrorism versus Insurgency" for a more detailed and technical discussion on this account. Both terms, insurgency and terrorism, are used in this study according to the original study's approach when defining the PKK.

92. Ersel Aydinli, and Nihat Ali Ozcan. "The conflict resolution and counterterrorism dilemma: Turkey faces its Kurdish question," Terrorism and Political Violence 23, no. 3 (2011): 438-57; Michael M. Gunter, "The Kurdish question in perspective," World Affairs 166, no. 4 (2004): 197-205.; Kirişci and Winrow, The Kurdish Question and Turkey; Matthew Kocher, "The decline of PKK and the viability of a one-state solution in Turkey," Democracy and Human Rights in Multicultural Societies 93 (2007); Ünal, Counterterrorism in Turkey.

93. Güneş Murat Tezcür, "Ordinary people, extraordinary risks: Participation in an ethnic rebellion," American Political Science Review 110, no. 2 (2016): 247-264. 
94. Ünal, "Is It Ripe Yet?"; Ünal, Counterterrorism in Turkey.

95. Kim and Yun, "What Works?."

96. Kocher, "The Decline of the PKK and the Viability of a One-State Solution in Turkey."

97. Ünal, Counterterrorism in Turkey; Ünal, "Counterinsurgency."

98. Aydınlı, "Between Security and Liberalization."

99. Kayhan-Pusane, "Turkey’s Kurdish Opening," 728.

100. Ünal, "Is It Ripe Yet?"

101. The PKK employed unilateral ceasefires for various strategic and pragmatic reasons, some of which include recouping, attempted resolution initiatives, pre-election periods, and so forth (beyond the scope and focus of this study). Except for one ceasefire during the resolution process Turkey did not acknowledge them and continued with military operations. And there existed violent incidents even in this period.

102. Casualties include Turkey's CT operations in N. Iraq that serves as the PKK's safe haven.

103. Personal Communication with Erin Miller in 2007, a senior consultant for the GTD program based in University of Maryland.

104. Irfan Ciftci and Sedat Kula, "The Evaluation of the Effectiveness of Counterterrorism Policies on the PKK-inflicted Violence during the Democratization Process of Turkey," Journal of Terrorism Research, 6/1 (2015).

105. Patrick T. Brandt, and John T. Williams. Multiple time series models. No. 148 (Sage, 2007).

106. Walter Enders, "Appied Econometric Time Series Fourth Edition," (2015).

107. Frey, Dealing with Terrorism; Turk, "Confronting Enemies Foreign and Domestic"; Nevin, "Retaliating".

108. A reduced form of the VAR model takes each variable as a linear function of its own past values and the past values of all other endogenous variables and serially uncorrelated error terms. See Stock and Watson, "Vector autoregressions."

109. The lag length for the standard VAR model is determined based on the Lag Order Selection Results, see Appendix-B.

110. This VAR model is built from a parsimony standpoint, reflecting a match with the available data, and they are also naive for the sake of brevity and simplicity in the interpretation of the results.

111. Enders and Sandler, "The Effectiveness of Antiterrorism Policies".

112. Impulse responses trace out the response of current and future values of each of the variables in the system to a one-unit increase in the current value of one of the VAR errors. So, in this study, the impulse response function shows the response of PKK-induced violence to a one standard deviation increase/shock (over the error term) in the incapacitated PKK members.

113. Brandt and Williams, Multiple Time Series Models.

114. Brandt and Williams, Multiple Time Series Models; James H. Stock, and Mark W. Watson. "Vector Auto-regressions," Journal of Economic perspectives (2001): 101-115.

115. Appendix-B includes all of the preliminary steps/procedures of VAR estimates with specific test results. These include basic themes of the VAR, Block Exogeneity Test, Augmented Dickey-Fuller Test, Akaike information criterion (AIC) and the Final prediction error (FPE), Serial Correlation LM, and Stability test.

116. Results are statistically significant where both error lines (dashed lines) are away (either above or below) from the zero-line indicating 0.95 confidence level.

117. To plot the results for all the analyses, the author used E-views 11, a multiple time series analysis software package.

118. Mathew Kocher, "The Decline of the PKK and the Viability of a One-State Solution in Turkey" (see note 3 above).

119. Abdullah Öcalan, Kürdistan Devriminin Yolu (Manifesto) (Köln, Germany: Weşanên serxwebûn, 1978).

120. Ünal, "Counterterrorism in Turkey." 
121. Region and emergency rule are, throughout the paper, refer to Turkey's southeast and east region that is populated with Kurds and where the PKK claimed independence. Most of this region was under emergency rule between 1987 and 2002.

122. Ünal, "Strategist or Pragmatist."

123. Ünal, "Counterinsurgency."

124. Kayhan-Pusane, "Turkey's Kurdish Opening," 81; Aydınl, "Between Security and Liberalization."

125. "Historical documentary on the PKK's withdrawal in 1999," accessed in May 10, 2018, https://www.youtube.com/watch?v=Eezt7TaFDLY.

126. Abdullah Öcalan, "There could be either Military or Political Solution in 1994," Serxwebun, 148/4 (April 1994) available at http://www.serxwebun.org/arsiv/148/.

127. There was not a collective state approach and a consensus on resolving the conflict with a conciliatory approach or with a viable exit strategy.

128. Ünal, "Is It Ripe Yet?."

129. DiMaggio and Powell, "The iron cage revisited"; Levinthal, "Organizational adaptation and environmental selection"; Posen, "Nationalism".

130. Adler, "Complex Deterrence in the Asymmetric-Warfare Era"; Arreguin-Toft, "Unconventional Deterrence," 204; Malka, "Asymemetrical Deterrence," 15.

131. Turk, "Confronting Enemies Foreign and Domestic"; Braithwaite, "Thinking Critically"; Frey, Dealing with Terrorism; Nevin, "Retaliating."

132. Frey, Dealing with Terrorism; Frey and Luechinger, "How to Fight Terrorism."

133. Ünal, "Is It Ripe Yet?," 11.

134. Ünal, Counterterrorism in Turkey.

135. KCK is the successor of Koma Komalen Kurdistan (KKK) created in 2005 by ÖÖcalan as part of his Democratic Confederalism concept and vision for pro-PKK Kurds inhabiting Turkey, Syria, Iraq, and Iran.

136. Ünal, "Is It Ripe Yet?"

137. William Zartman, "Negotiating İnternal, Ethnic and İdentity Conflicts in a Globalized World," International Negotiation 11, no. 2 (2006): 261.

138. Ibid.

139. Ibid.

140. Ünal, "Counterinsurgency."

141. Casualty figures for security forces and civilians are reliable as they are part of a related judicial process.

142. “Terror Results for 265 days," Milliyet, March, 28 2016, accessed on June 17, 2016, http:// www.milliyet.com.tr/tsk-bilancoyu-acikladi-4-bin-432-gundem-2217174/.

143. Berkay Mandırac1, "International Crisis Group: Turkey's PKK Conflict: The Death Toll," https://www.crisisgroup.org/europe-central-asia/western-europemediterranean/turkey/tur key-s-pkk-conflict-death-toll (accessed July 30, 2016).

144. See Appendix-A (Table A-2) for detailed incapacitation figures.

145. "Turkish Army, so far, finished the PKK 5 times," Milliyet, July 6, 2010, accessed October 17, 2015, http://www.milliyet.com.tr/sozun-bittigi-yerdeyiz-/siyaset/haberdetay/06. 07.2010/1259717/default.htm.

146. Schelling, Arms and Influence, 34.

147. Frey, Dealing with Terrorism.

148. Michael Howard, “When are wars decisive?” Survival 41, no. 1 (1999): 126-135.

\section{Notes on contributors}

Mustafa Cosar Unal is an Adjunct Associate Professor at Bilkent University. He received his Ph.D. in 2009 in Public Policy and Administration from the University of Maryland. He served for 16 years in the Turkish Intelligence Department and held different managerial positions in which he dealt with strategic level analyses of terrorism and insurgency. His research is mostly on terrorism 
and other types of asymmetric conflict, conflict management and resolution, insurgency, counterinsurgency (COIN), counterterrorism (CT), COIN doctrines and strategies, intelligence, and national security. His recent publications include: Counterterrorism in Turkey: Policy Choices and Policy Effects toward the Kurdistan Workers' Party (PKK) (Routledge); “Opening a Door for Return to Home: Impact and effectiveness of Turkish Repentance Laws as a counterterrorism measure," in Studies in Conflict and Terrorism; "Strategist or Pragmatist: A Challenging Look at Ocalan's Retrospective Classification and Definition of PKK's Strategic Periods of 1973-2012," in Terrorism \& Political Violence; "The Kurdistan Workers' Party (PKK) and Popular Support: Counterterrorism towards an insurgency nature," in Small Wars \& Insurgencies; "Terrorist or Insurgency: A Conceptual Analysis," in Crime, Law and Social Change; "Counterinsurgency and Military Strategy: An analysis of Turkish Army's COIN Doctrines/Strategies," in Military Operations Research; "Is it ripe yet? Resolving Turkey's 30 years of conflict with the PKK" in Turkish Studies; and "Do terrorists make a difference in criminal networks?" in Social Networks.

Petra Cafnik Uludăg is an Adjunct Instructor at Bilkent University and TED University in Ankara. She received her Ph.D. in 2017 in Political Science from Bilkent University. In her research she is focusing on the interaction of media and politics, discursive practices, conceptual history, social movements and terrorism. Her recent publications include "Beware the winter is coming! Arab Spring in the global media" in Critical Studies in Media Communication and "Insisting on victory" with Mustafa Coşar Ünal in Revista Científica General José María Córdova.

\section{ORCID}

Mustafa Cosar Unal (D) http://orcid.org/0000-0001-8671-9574

Petra Cafnik Uludağ (1) http://orcid.org/0000-0002-3110-8706 


\section{APPENDIX - A}

Table A-1. Casualty figures in the Turkey- PKK conflict between 1984 and 2018.

\begin{tabular}{|c|c|c|c|c|}
\hline & & Killed & Injured & Casualty \\
\hline \multirow[t]{5}{*}{ Security Forces } & Military & 5,438 & 13,334 & 18,772 \\
\hline & Police & 566 & 5,073 & 5,646 \\
\hline & Village Guard (GKK) & 1,469 & 2,110 & 3,579 \\
\hline & Total & 7,473 & 20,517 & 27,997 \\
\hline & $\%$ Security force & $54.87 \%$ & $67.12 \%$ & $63.35 \%$ \\
\hline \multirow[t]{5}{*}{ Non-combatants } & Civilian & 5684 & 10050 & 15734 \\
\hline & Teacher & 124 & 0 & 124 \\
\hline & Government staff & 338 & 0 & 336 \\
\hline & Total & 6,146 & 10,050 & 16,194 \\
\hline & $\%$ Civilian and Gov. Staff & $45.13 \%$ & $32.88 \%$ & $36.65 \%$ \\
\hline \multirow[t]{3}{*}{ Total casualties } & & Killed & Injured & Casualty \\
\hline & $\%$ Total & 13,619 & 30,567 & 44,191 \\
\hline & & $100 \%$ & $100 \%$ & $100 \%$ \\
\hline
\end{tabular}

Table A-2. Killed, injured, captured, and surrendered PKK members (1984-2018).

\begin{tabular}{lcc}
\hline & INCAPACITATED PKK MILITANTS & \\
\hline PKK's armed militants & Killed & Injured \\
& 32,562 & 1,566 \\
Total casualty (killed and injured): 34,128 & & Captured \\
PKK's armed militants & Surrendered/ & (Alive) \\
& Capitulated & 8,102 \\
& 7,146 & \\
Total incapacitated (killed, injured, and captured): 42,230 & & \\
\hline
\end{tabular}




\section{APPENDIX - B}

\section{Vector Auto Regression as the analysis technique}

To address the RQ, the author used the Vector autoregression technique, which particularly analyzes the underlying correlation among multiple time series variables to identify the dynamic structure among those variables. ${ }^{i}$ This is because, as opposed to other approaches to time series analyses, VAR models do not assume to know the correct structure of the underlying relationships that generated the multiple time series. ${ }^{\text {ii }}$ VAR is specifically designed to capture and characterize the uncertainties and structural dynamics among the time series in an unrestricted manner without precisely knowing the true dynamics and relationships in most cases. ${ }^{\text {iii }}$ Therefore, VAR is a multivariate autoregressive model in which each endogenous variable is regressed on its past values and past values of the other endogenous variables and current values of the exogenous variables in the system. So, VAR, as a model to analyze the dynamic impact of random disturbances on the system of variables, does not need structural modeling because it treats every endogenous variable in the system as a function of the lagged values of all of the endogenous variables in the system. In sum, VAR is an $n$-equation, $n$-variable model ${ }^{\text {iv }}$ in which each variable in the model is explained by its own lagged values, as well by the lagged values of the remaining $(n-1)$ variables for the endogenous variables and current values of the exogenous variables. ${ }^{\mathrm{v}}$

The VAR model for this study is built from a parsimony standpoint, reflecting a match with the available data, and they are also naive for the sake of brevity and simplicity in the interpretation of the results. Sandler and Enders used a similar model, ${ }^{\mathrm{vi}}$ where they analyzed the substitution effect among different modes of attacks in transnational terrorism. In this framework, the effect of terrorist violence and use of force are allowed to affect each other so the retaliatory effect of use of force can be captured. By using this model, the author plotted the impulse response function to identify the dynamic interrelation between INCAPTER and VIOLENCE.

As many other statistical analysis techniques, VAR analysis also needs to meet certain criteria/ assumptions for reliable results and inferences; i.e., non-existence of unit root/stationarity, determining appropriate lag length based on fit statistics; uncorrelated residuals and etc. All necessary preliminary tests were conducted and results came out meeting the assumptions. In that, results indicated that none of the variables has a unit root and there is no serial correlation problem among the residuals and white noise disturbances. Yet, the appropriate lag lengths are specified based on fit statistics (e.g., Schwarz Information Criterion).

\section{Preliminary tests for VAR analysis}

VAR estimates need to have certain requirements for reliable results. These include, first, determining whether the variables are endogenous or exogenous (based on the theory and certain tests). Second, each time series variable must not have a unit root. Third, the appropriate lag length has to be specified based fit statistics (e.g., Schwarz Information Criterion). Fourth, there should not be any serial correlation problem among the residuals and white noise disturbances. The author conducted related tests for each of these criteria that VAR estimates have to meet. In this regard, VAR estimates are conducted by the following procedure for both datasets:

-Running the unit root test (Augmented Dickey Fuller) to analyze the stationarity (unit root) for all series used in VAR estimates,

-Granger Causality/Block Exogeneity Test (pair wise, for all possible pairs),

-Preliminary VAR estimates,

-Determining the lag length,

-Running VAR estimates,

-Specification tests (residual test for serial correlation),

-Stability Tests (e.g., CUSUM TEST) 
-Interpretation of VAR Models (impulse response function).

When t-statistics are used for hypothesis testing, the critical value of t-statistics for the confidence level 0.10 is 1.65 , for 0.05 confidence level it is 1.96 , and for 0.005 confidence level it is 2.57 . These $\mathrm{t}$-statistics/scores are based on the degree of freedom in which the sample size is more than 30 and considered large enough to reflect a normally distributed sample. ${ }^{\text {vii }}$

\section{Unit root test: Stationarity}

Testing for unit root behavior of each series (variable) in the VAR system is important, because existence of unit root strongly indicates that there is a correction mechanism and thus the test for Granger Causality is biased. ${ }^{\text {vii }}$ The results indicated that variables that are used in this study do not have unit root problem. Results are presented in Table B-1, by testing the null hypothesis (H0): "Variable X has a unit root." The critical t-statistic values for (1\%) 0.01 and (5\%) 0.05 levels are specified as well as the probability values for each variable tested for unit root (stationarity). ${ }^{\text {ix }}$ Individual results for each variable indicated no unit root problem based on the t-statistic scores and p-values. That is, we can reject the null hypotheses: "variables have unit root" at the 0.01 level for all related variables (the produced t-scores are higher than critical t-values of $1 \%$ ). ${ }^{\mathrm{x}}$

Table B-1. Unit root test results for INCAPTER

\begin{tabular}{|c|c|c|c|}
\hline \multicolumn{4}{|c|}{ Null Hypothesis: _INCAPTER has a unit root } \\
\hline \multicolumn{4}{|l|}{ Exogenous: Constant } \\
\hline \multicolumn{4}{|c|}{ Lag Length: 2 (Automatic - based on SIC, maxlag=15) } \\
\hline & & t-Statistic & Prob.* \\
\hline \multicolumn{2}{|c|}{ Augmented Dickey-Fuller test statistic } & -4.532800 & 0.0002 \\
\hline \multirow[t]{3}{*}{ Test critical values: } & $1 \%$ level & -3.452519 & \\
\hline & $5 \%$ level & -2.871195 & \\
\hline & $10 \%$ level & -2.571986 & \\
\hline
\end{tabular}

Table B-2. Unit root test results for VIOLENCE

\begin{tabular}{|c|c|c|c|}
\hline \multicolumn{4}{|c|}{ Null Hypothesis: _VIOLENCE has a unit root } \\
\hline \multicolumn{4}{|c|}{ Exogenous: Constant } \\
\hline \multicolumn{4}{|c|}{ Lag Length: 0 (Automatic - based on SIC, maxlag=15) } \\
\hline & & t-Statistic & Prob.* \\
\hline \multicolumn{2}{|c|}{ Augmented Dickey-Fuller test statistic } & -9.636840 & 0.0000 \\
\hline \multirow[t]{3}{*}{ Test critical values: } & $1 \%$ level & -3.452366 & \\
\hline & $5 \%$ level & -2.871128 & \\
\hline & $10 \%$ level & -2.571950 & \\
\hline
\end{tabular}




\section{Granger Causality (GCT)}

The GCT, suggested by Granger in 1969, addresses the question of how one variable can forecast the other, implying a meaningful endogenous relationship between the two time series variables. ${ }^{\mathrm{xi}}$ If Variable $\mathrm{X}$ does not Granger cause [a change in] the Variable $\mathrm{Y}$, then we can say that there is no meaningful relationship between Variable X and Y. In other words, Variable $\mathrm{Y}$ is not informative about the future values of the Variable $\mathrm{X}$ : "if an event $\mathrm{Y}$ is the cause of another event $\mathrm{X}$ then the event $Y$ should precede the event X" xii While this premise can be true, there is criticism that such a relationship does not imply causality. ${ }^{\text {xii }}$ However, the existence of Granger Causality between two time series variables strongly indicates endogeneity, a meaningful relationship. Hamilton ${ }^{\text {xiv }}$ indicated that in general, some time series variables are found to be predictors of each other and this does not mean that these series cause each other. Rather, they are very informative on each other's future values, especially in time series that reflect a forward-looking behavior. As part of this research, Granger Causality Test was run to address whether or not there is a meaningful relationship between the INCAPTER and VIOLENCE, and INCAPTER and NVIOLENT (the number of violent attacks as a different measurement of violence). Results are portrayed in Table B-3.

Table B-3 Pairwise Granger Causality Test results

\begin{tabular}{|c|c|c|c|}
\hline \multicolumn{4}{|l|}{ Pairwise Granger Causality Tests } \\
\hline \multicolumn{4}{|l|}{ Sample: 1994M05 2018M12 } \\
\hline \multicolumn{4}{|l|}{ Lags: 5} \\
\hline Null Hypothesis: & Obs & F-Statistic & Prob. \\
\hline _INCAPTER does not Granger Cause_VIOLENCE & 291 & 2.39903 & 0.0375 \\
\hline _VIOLENCE does not Granger Cause_INCAPTER & & 1.87472 & 0.0988 \\
\hline
\end{tabular}

\section{Lag length specification}

Determining the lag length in VAR estimates is important because the result of the properties of VAR coefficients and estimations depends on the specified lag length of the VAR analysis. Lag length basically indicates the number of lags that the VAR system would refer to retrospective values of each endogenous variable and treats each lag as a different endogenous variable to capture the effects of previous values on the present values of the endogenous variables. For example, the first lag of an endogenous variable refers to the previous month's value of that particular variable, since the data are restructured to have monthly interval data points in this study.

For the VAR estimates in this study, the author used fit statistics of the Akaike information criterion (AIC) and the Final prediction error (FPE) to specify the lag length for the constructed VAR models. Test for the lag length criteria, from the preliminary VAR estimates for both datasets are respectively plotted in Table B-4 and Table B-5. As indicated in tables, the structural system of the VAR model selected the lag length as " 6 " (marked with asterisk in tables) based on the AIC and FPE. 
Table B-4. Lag Order Selection Results by AIC and FPE Information Criteria

\begin{tabular}{|c|c|c|c|c|c|}
\hline \multicolumn{6}{|c|}{ VAR Lag Order Selection Criteria } \\
\hline \multicolumn{6}{|c|}{ Endogenous variables:_VIOLENCE _INCAPTER } \\
\hline \multicolumn{6}{|c|}{ Exogenous variables: $\mathrm{C}$} \\
\hline \multicolumn{6}{|c|}{ Sample: 1994M05 2018M12 } \\
\hline \multicolumn{6}{|c|}{ Included observations: 288} \\
\hline Lag & $\log \mathrm{L}$ & LR & FPE & AIC & $\mathrm{HQ}$ \\
\hline 0 & -2958.451 & NA & 2907869. & 20.55869 & 20.56888 \\
\hline 1 & -2861.421 & 192.0384 & 1524064. & 19.91264 & 19.94323 \\
\hline 2 & -2854.048 & 14.48933 & 1488792. & 19.88922 & 19.94019 \\
\hline 3 & -2835.992 & 35.23349 & 1350357. & 19.79161 & 19.86297 \\
\hline 4 & -2830.863 & 9.937494 & 1339840. & 19.78377 & 19.87552 \\
\hline 5 & -2818.797 & $23.21086^{*}$ & $1266893 .^{*}$ & $19.72776^{*}$ & $19.83989^{*}$ \\
\hline 6 & -2816.141 & 5.072238 & 1278835. & 19.73709 & 19.86961 \\
\hline 7 & -2815.892 & 0.472937 & 1312667. & 19.76314 & 19.91604 \\
\hline 8 & -2813.543 & 4.419716 & 1327922. & 19.77461 & 19.94790 \\
\hline \multicolumn{6}{|c|}{ * indicates lag order selected by the criterion } \\
\hline \multicolumn{6}{|c|}{ FPE: Final prediction error } \\
\hline \multicolumn{6}{|c|}{ AIC: Akaike information criterion } \\
\hline HQ: & n informat & & & & \\
\hline
\end{tabular}

\section{Specification test for serial correlation}

For the VAR estimation to be robust, residuals should be uncorrelated over lagged time periods. There are multiple ways to test for the existence of serial correlations of the residuals; however, all these proposed tests are asymptotically equivalent. ${ }^{\mathrm{xv}}$ The author used the Serial Correlation LM Test the VAR model to identify the autocorrelation, if any, between the different lags of variables over the five months period. As shown in Table B-5, the results for both datasets indicate no systematic serial correlation for VAR estimates at the determined lag 5. That is, results indicate that we cannot reject the null hypothesis (H0) of "there is no serial correlation." xvi

In addition to the test results for serial correlation, the author also ran a stability test for the constructed VAR model with specified lag length of " 5 ." Results, as shown in below figures, indicate that VAR estimates from both datasets satisfy the stability conditions.

First, as AR Roots graph idicate in figure B-1, the estimated VAR is table (stationary) since all roots lie inside the unit circle.

Second, authors ran the CUSUM test which gives the parameter stability of the constructed VAR model. It is based on the cumulative sum of the recursive residuals. As plotted in the figure B-2, the cumulative sum does not go outside the area between the two critical lines meaning that the constructed VAR model is stable.

\section{Interpretation of VAR results}

As mentioned in the previous paragraphs, VAR is designed to identify the interrelated dynamics among multiple variables in a time series. ${ }^{\text {xvii }}$ It is very typical of VAR analysis not to present and analyze the coefficients. This is because the coefficients mean nothing individually, especially for the endogenous variables. Rather, individual coefficients identify and describe the dynamics of the variables and, in turn, the behavior of the whole system. The inferences have to include and consider all of the [endogenous variables'] coefficients in the system at all distributed lag lengths. ${ }^{\text {xviii }}$ In the literature, VAR results are interpreted with alternative methods. These alternative methods that portray the interrelated dynamics among the variables are used to make inferences as suggested 
Table B-5. Serial Correlation LM Test

\begin{tabular}{|c|c|c|c|c|c|c|}
\hline \multicolumn{7}{|c|}{ VAR Residual Serial Correlation LM Tests } \\
\hline \multicolumn{7}{|c|}{ Date: 02/22/19 Time: $17: 30$} \\
\hline \multicolumn{7}{|c|}{ Sample: 1994M05 2018M12 } \\
\hline \multicolumn{7}{|c|}{ Included observations: 291} \\
\hline \multicolumn{7}{|c|}{ Null hypothesis: No serial correlation at lag $\mathrm{h}$} \\
\hline Lag & LRE* $^{*}$ stat & $\mathrm{df}$ & Prob. & Rao F-stat & df & Prob. \\
\hline 1 & 5.762552 & 4 & 0.2176 & 1.445534 & $(4,554.0)$ & 0.2176 \\
\hline 2 & 4.137230 & 4 & 0.3878 & 1.036302 & $(4,554.0)$ & 0.3878 \\
\hline 3 & 5.146862 & 4 & 0.2726 & 1.290371 & $(4,554.0)$ & 0.2726 \\
\hline 4 & 6.870740 & 4 & 0.1429 & 1.725247 & $(4,554.0)$ & 0.1429 \\
\hline 5 & 8.508389 & 4 & 0.0746 & 2.139623 & $(4,554.0)$ & 0.0746 \\
\hline 6 & 2.744170 & 4 & 0.6015 & 0.686502 & $(4,554.0)$ & 0.6015 \\
\hline \multicolumn{7}{|c|}{ Null hypothesis: No serial correlation at lags 1 to $\mathrm{h}$} \\
\hline Lag & $\mathrm{LRE}^{*}$ stat & $\mathrm{df}$ & Prob. & Rao F-stat & $\mathrm{df}$ & Prob. \\
\hline 1 & 5.762552 & 4 & 0.2176 & 1.445534 & $(4,554.0)$ & 0.2176 \\
\hline 2 & 6.420355 & 8 & 0.6003 & 0.802842 & $(8,550.0)$ & 0.6003 \\
\hline 3 & 12.52386 & 12 & 0.4046 & 1.046027 & $(12,546.0)$ & 0.4046 \\
\hline 4 & 30.29461 & 16 & 0.0165 & 1.921807 & $(16,542.0)$ & 0.0165 \\
\hline 5 & 40.91552 & 20 & 0.0038 & 2.089281 & $(20,538.0)$ & 0.0038 \\
\hline 6 & 45.42918 & 24 & 0.0052 & 1.934170 & $(24,534.0)$ & 0.0052 \\
\hline
\end{tabular}

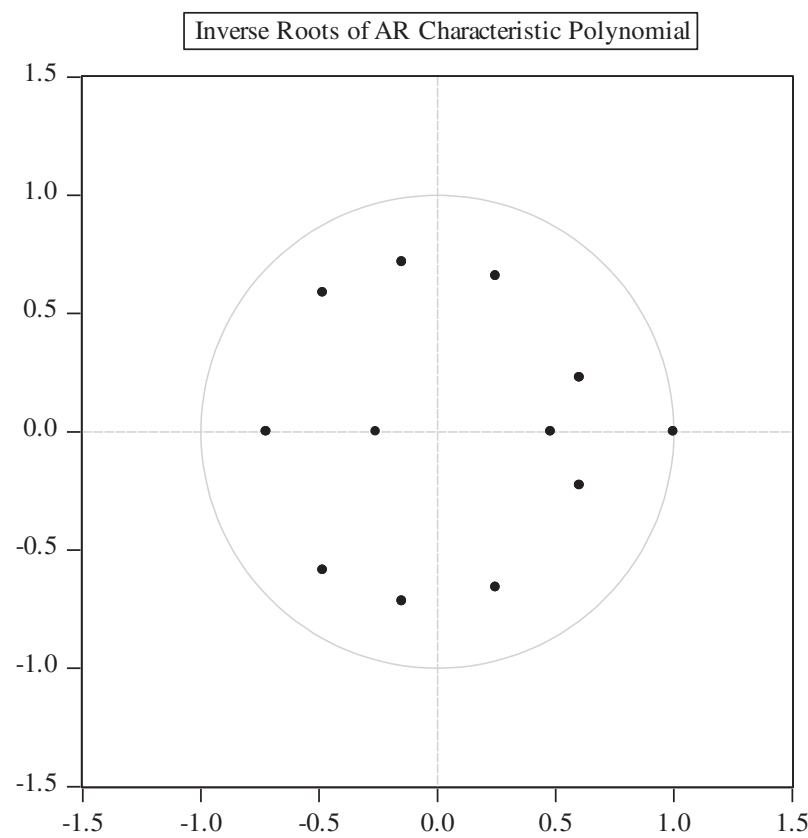

Figure B-1. Inverse Roots of AR Characteristic Polynomial 


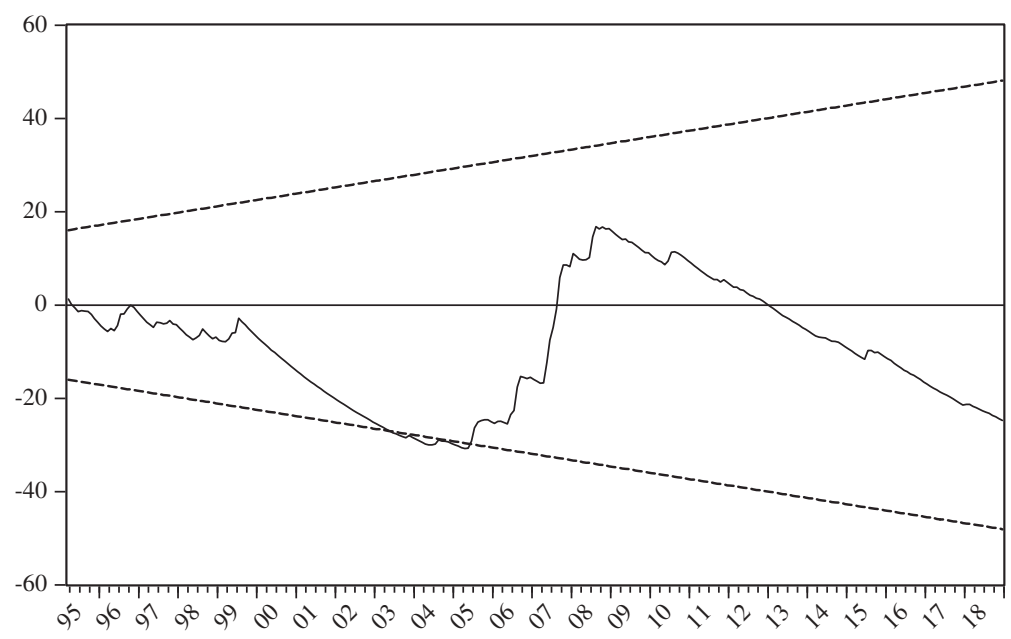

- Cumulative sum (CUSUM) of the recursive residuals

---. $5 \%$ Significance critical line

Figure B-2. Parameter stability (CUSUM) test

in the VAR literature. ${ }^{\mathrm{xix}}$ One of these methods is the impulse response function for the structural interaction between endogenous variables in the VAR system.

In the most generic definition, impulse responses trace out the response of current and future values of each of the variables in the system to a one-unit increase in the current value of one of the VAR errors. ${ }^{\mathrm{xx}}$ It is simply changing one error term while holding the others constant when the errors are uncorrelated across equations in the system. ${ }^{\mathrm{xxi}}$ So, in this study, the impulse response function shows the response of PKK-induced violence to a one standard deviation increase/shock (over the error term) in the incapacitated PKK members. All results are plotted through E-views 5.1, a multiple time series analysis software package.

\section{Bibliography}

Hamilton, James Douglas. Time series analysis. Vol. 2. Princeton: Princeton university press, 1994. James H. Stock, and Mark W. Watson. "Vector Auto-regressions", Journal of Economic perspectives, 15 no: 4 (2001): 101-115.

McClave, J. T., and F. H. Dietrich. "II 1988 Statistics." Dellen PublishingCompany, San Francisco, CA (1988).

Patrick T. Brandt, and John T. Williams. Multiple Time Series Models. Series: Quantitative Applications in the Social Sciences. California, London, Sage Publications, 2007

Walter, Enders. Applied econometric time series. John Wiley \& Sons, 2003.

Walter Enders and Todd Sandler. "The Effectiveness of Antiterrorism Policies: A VectorAutoregression-Intervention Analysis”, American Political Science Review 87, no. 04 (1993): 829844. 


\section{Notes}

1. Patrick T. Brandt, and John T. Williams. "Multiple Time Series Models. Series: Quantitative Applications in the Social Sciences." California, London, Sage Publications (2007); James H. Stock, and Mark W. Watson. "Vector Auto-regressions", Journal of Economic perspectives (2001): 101-115.

2. Brandt and Williams, "Multiple Time Series Models" p. 9.

3. Ibid.

4. Walter, Enders. Applied econometric time series. John Wiley \& Sons, 2003.

5. Stock and Watson, "Vector Auto-regressions"

6. Walter Enders and Todd Sandler. "The Effectiveness of Antiterrorism Policies: A VectorAutoregression-Intervention Analysis", American Political Science Review 87, no. 04 (1993): 829-844.

7. McClave, J. T., and F. H. Dietrich. "II 1988 Statistics." Dellen PublishingCompany, San Francisco, CA (1988).

8. Brandt and Williams, "Multiple Time Series Models"

9. Specification of lag length for all preliminary tests is based on default selection by the system itself. For the actual VAR analysis, specific test is run to determine the lag length for the entire VAR systems.

10 If a series is not stationary, it does not converge normal distribution at the convergence rate of $\frac{\partial}{\partial t}\left(\alpha_{i} \rho_{i}\right)+\nabla .\left(\alpha_{i} \rho_{i} \overline{U_{i}}\right)=0$. So, we cannot use the critical T-statistics produced for normal distribution. Therefore, unit root test produced individual $\mathrm{T}$-statistics for each variable tested against stationarity and specific T-statistics at $1 \%$ and $5 \%$ confidence level are indicated in the related Table.

11. Hamilton, James Douglas. Time series analysis. Vol. 2. Princeton: Princeton university press, 1994; Brandt and Williams, "Multiple Time Series Models;" Stock and Watson, "Vector autoregressions."

12. Ibid.

13. Causality requires three criteria in the most generic definition: existence of a temporally consistent relationship; a statistically significant correlation; and a non-spurious relationship. While the first two criteria can be tested, the relationship being non-spurious and the direction of the relationship cannot be determined other than with related theories that explain the relationship between the variables. Yet, a result of non-causality from the Granger Causality Test does not mean that there is no contemporaneous correlation between the variables, it only means that the past values of variables are not predictive for the current values of other variable.

14. Hamilton, Time series analysis p.307

15. Ibid.

16. If any of the serial correlation tests show evidence of serial correlation in residuals, the solution is to add additional lags into each equation in the VAR analysis.

17. Brandt and Williams, "Multiple Time Series Models;" Enders, Applied econometric time series.

18. Brandt and Williams, "Multiple Time Series Models." p.65; Hamilton, Time series analysis; Stock and Watson, "Vector auto-regressions."

19. Ibid; Enders, Applied econometric time series.

20. Impulse response function assumes that the error (that belongs to one of the variables in the system and increased at one unit to get the response function) returns to zero in subsequent periods (decays/fades out) and all other errors are equal to zero.

21. Brandt and Williams, "Multiple Time Series Models;" Stock and Watson, "Vector autoregressions." 


\section{APPENDIX - C}

\section{Results of the quantitative analysis with different dataset and with different measurement of terrorism}

The VAR estimates from both datasets, the governmental dataset (GOVDAT hereafter) and the institutional dataset (INSDAT hereafter), revealed that incapacitating PKK militants did not have a significant decreasing impact on PKK violence, which revealed that deterrence policies were ineffective in the overall sense to mitigate the PKK surge. In fact, sole annihilation of PKK terrorists through eliminationist deterrence efforts was found to be counterproductive in the short term. Therefore, the results strongly contradict the logic of the motto "until no terrorist remains" implying that incapacitation strategy failed to realize the pursued policy goal as reflected in the motto.

The specifics for each dataset indicate the results for:

(i) the relationship between INCAPTER and VIOLENCE (number of casualties), where the response of VIOLENCE as a result of incapacitation efforts is analyzed,

(ii) the relationship between INCAPTER and NVIOLENT in which the response of the number of violent incidents (NVIOLENT) is analyzed as a different measurement of PKK violence (rather than the number of casualties)

(iii) how state security forces (mostly military units) responded to PKK-induced violence-the response of INCAPTER to the PKK-initiated VIOLENCE-as analyzed through the VAR estimates.

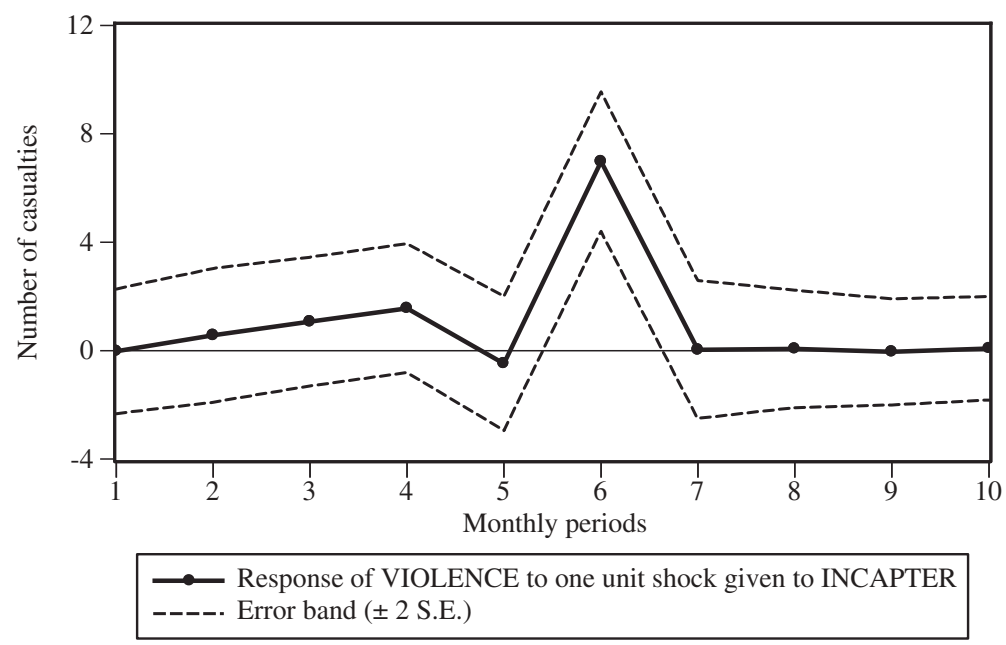

Figure C-1. The response of VIOLENCE to one S.D. impulse in INCAPTER - GOVDAT

How incapacitation affected PKK-induced violence is plotted in Figure C-1 for the GOVDAT and in Figure C-2 for the INSDAT. The horizontal solid lines in both figures denote the change (response) in the violence level (VIOLENCE) after one-unit (standard deviation) shock/impulse was given to the incapacitation (INCAPTER) to see how the violence level was impacted over a tenmonth period. The horizontal dashed lines refer to the error band around the impulse function result. ${ }^{1}$ For the official GOVDAT, the response of VIOLENCE to one unit shock/innovation given to the INCAPTER results in about seven more casualties in the sixth month, as shown in Figure C- 
$1 .^{2}$ Subsequent to the slight increase, the impulse effect shows a steep increase in the sixth month and then decay.

VAR estimates for the institutional data indicate similar results. The response of VIOLENCE to a one-unit shock/innovation given to the INCAPTER results in about seven more casualties-but in the fourth month, as shown in Figure C-2. As opposed to the GOVDAT results, the INCAPTER's effect starts with a steady increase and reaches its peak in the fourth month and then gradually decays and fades away by the tenth month. The results from both datasets indicate that incapacitating PKK militants did not have a decreasing impact on PKK-initiated violence. Rather, it yielded a counterproductive impact, implying that the incapacitated PKK militants are easily replaced with new recruits, enabling the PKK to continue employing retaliatory violent attacks despite such intense incapacitation efforts. ${ }^{3}$

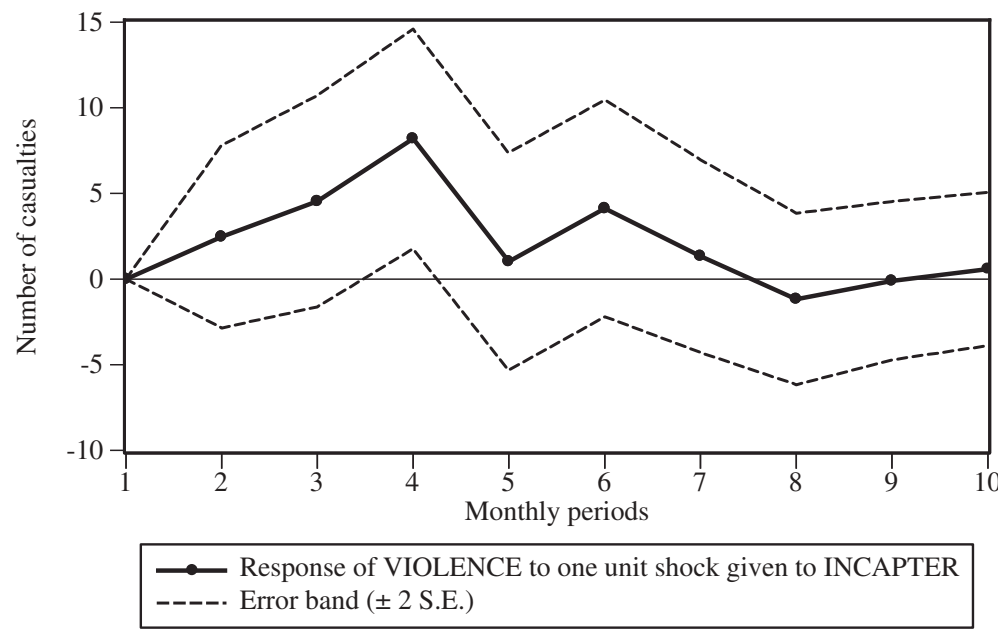

Figure C-2. The response of VIOLENCE to one S.D. impulse in INCAPTER - INSDAT

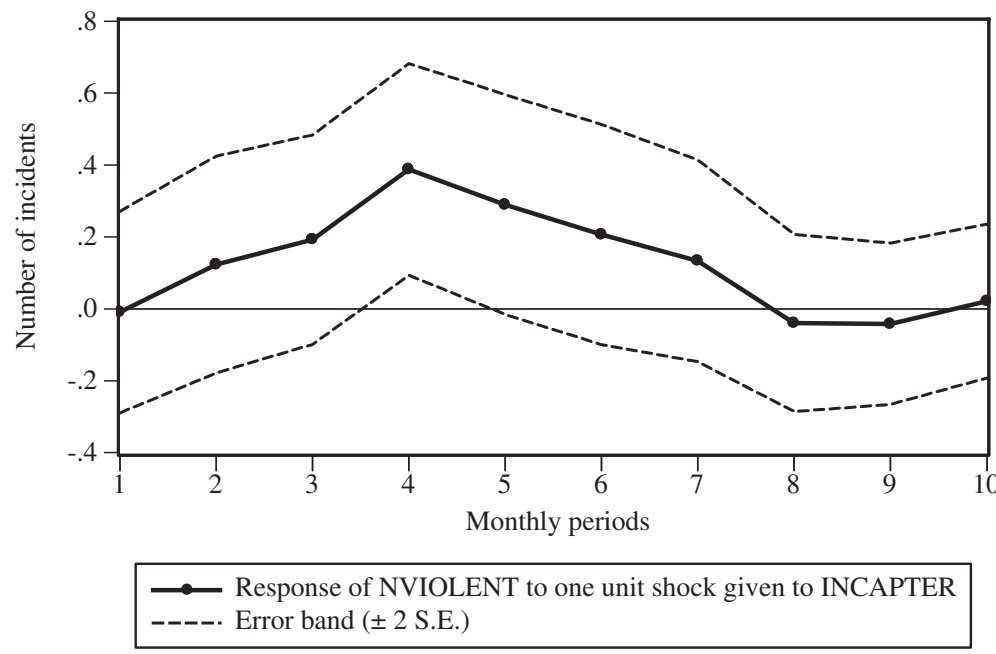

Figure C-3. The response of NVIOLENT to a one S.D. impulse in INCAPTER - GOVDAT 


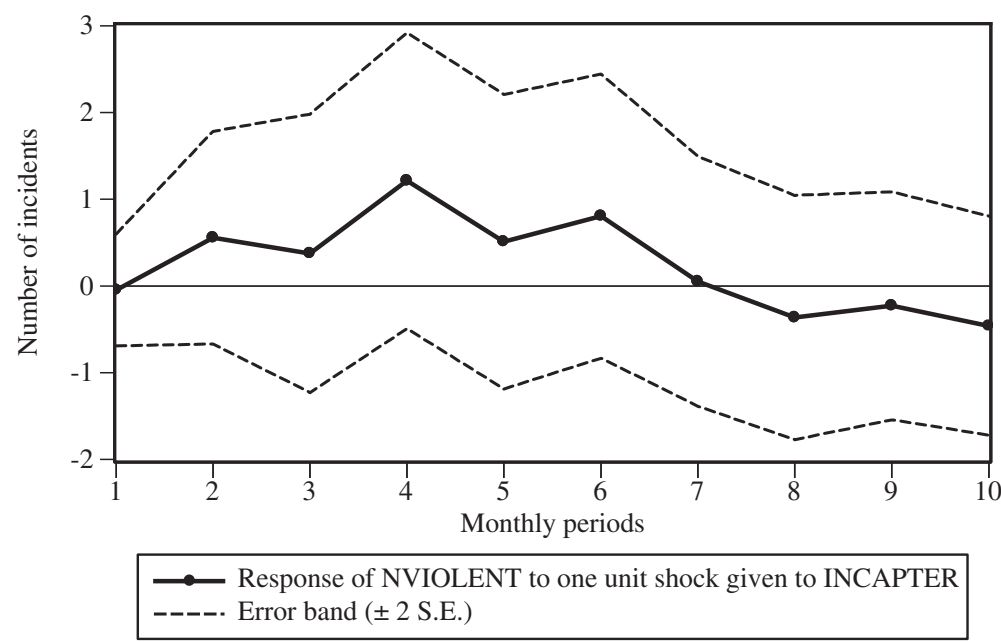

Figure C-4. The response of NVIOLENT to a one S.D. impulse in INCAPTER - INSDAT

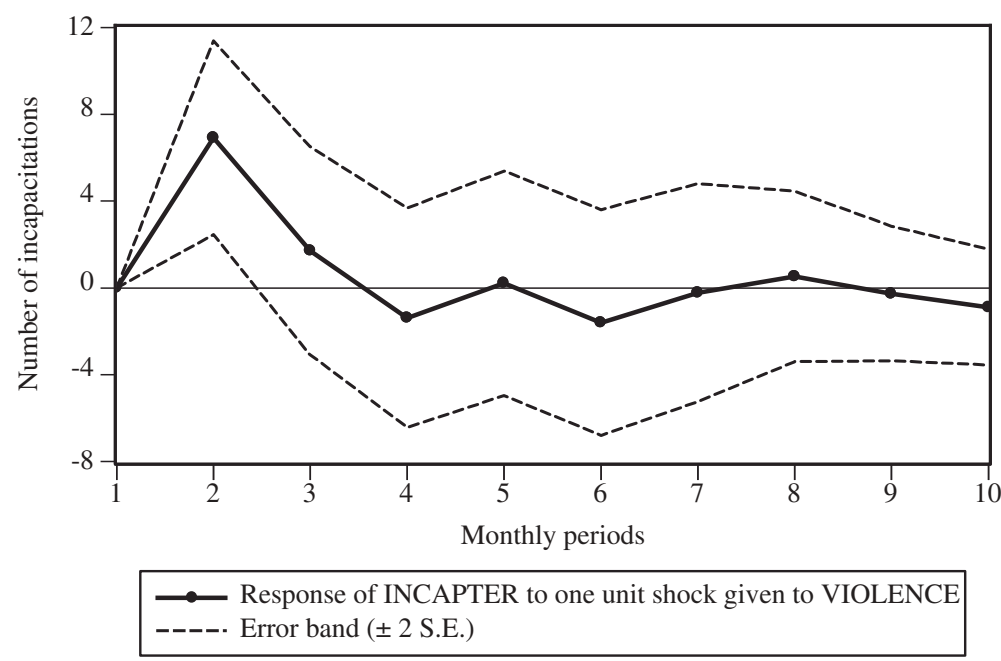

Figure C-5. The response of INCAPTER to a one S.D. impulse in VIOLENCE - GOVDAT

In addition to verifying the results using different datasets, this study also analyzes the aforementioned RQ-to identify the impact of incapacitation on PKK-induced violence-by utilizing different measurements of PKK violence. Instead of the number of casualties resulting from PKK attacks (the most common measurement of the degree of violence), the number of violent attacks conducted by the PKK is used as an alternative variable measuring PKK violence. VAR estimates indicate similar results. As displayed in Figure C-3 for the GOVDAT and in Figure C-4 for the INSDAT, violent PKK incidents (NVIOLENT) increase after incapacitation, peaking in the fourth month and then decaying until the tenth. However, while the results for the GOVDAT are 


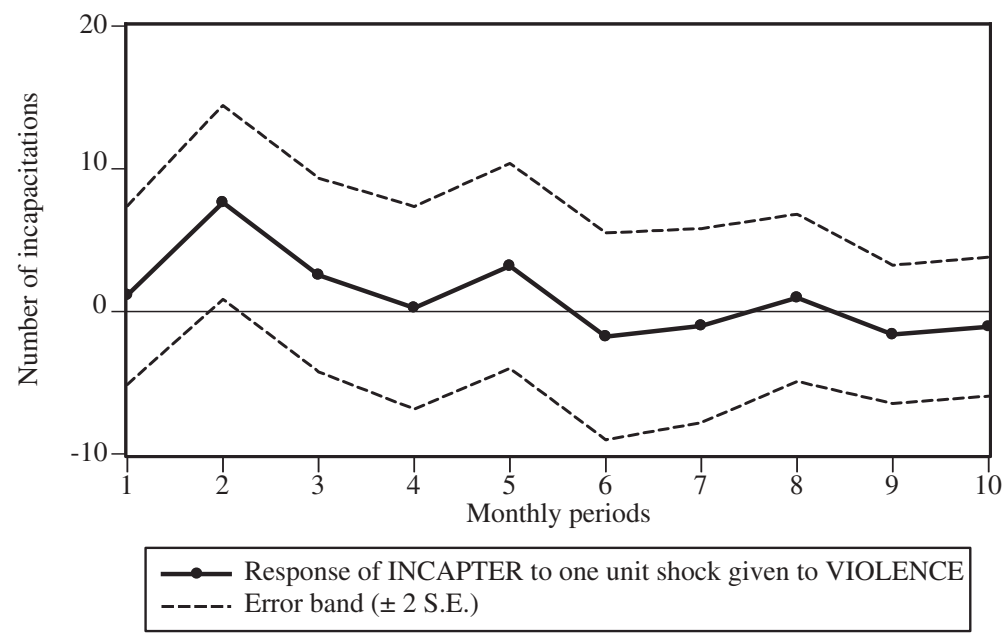

Figure C-6. The response of INCAPTER to a one S.D. impulse in VIOLENCE - INSDAT

significant for the fourth month (since both error lines are above zero), the INSDAT results did not have any statistical relevance.

To see how the security forces' incapacitation (INCAPTER) effort is affected, an impulse shock is given to PKK violence (VIOLENCE). The results for GOVDAT and INSDAT are plotted in Figure C-5 and Figure C-6, respectively. The results from both datasets clearly indicate that security forces responded immediately to PKK attacks. As shown in Figures C-5 and C-6, results from both datasets indicate an immediate and statistically significant spike in the incapacitation efforts starting from the second period. However, these incapacitation efforts gradually fall after peaking during the second month.

In the end, the results from the VAR analyses indicated that the paradigm of incapacitationoriented deterrence aiming to end the PKK surge by annihilating "until no terrorist remains" did not help mitigate the PKK violence. As elaborated in the following section, the results shed light on Turkey's recognition of the military stalemate (in total elimination of PKK terrorists) and its negative impact on both human loss and economic cost. Thus, this led to Turkey's switch to a more conciliatory approach after long years of sole application of a eliminationist deterrence approach that is not used as a policy tool nor was it tied to a viable political end-state and an aligned grand strategic approach (e.g., political solution/exit strategy).

\section{Notes}

1. According to the most generic definition, impulse responses trace out the response of current and future values of each of the variables in the system to a one-unit increase in the current value of one of the VAR errors. It is simply changing one error term while holding the others constant when the errors are uncorrelated across equations in the system. So, in this study, the impulse response function shows the response of PKK-induced violence to a one standard deviation increase/shock (over the error term) in the incapacitated PKK members.

2. Results are statistically significant where both error lines (dashed lines) are away (either above or below) from the zero line indicating 0.95 confidence level. In this case, it is above in the sixth period for the GOVDAT and above in the fourth period for the INSDAT. This includes "0" in the third month. The results are statistically significant..

3. To plot the results for all the analyses, the author used E-views 5.1, a multiple time series analysis software package. 